\title{
Magnetic resonance imaging (MRI) in rectal cancer: a comprehensive review
}

\author{
Michael R. Torkzad • Lars Påhlman • Bengt Glimelius
}

Received: 24 May 2010 /Revised: 11 July 2010 / Accepted: 26 July 2010 / Published online: 15 August 2010

(C) European Society of Radiology 2010

\begin{abstract}
Magnetic resonance imaging (MRI) has established itself as the primary method for local staging in patients with rectal cancer. This is due to several factors, most importantly because of the ability to assess the status of circumferential resection margin. There are several newer developments being introduced continuously, such as diffusion-weighted imaging and imaging with $3 \mathrm{~T}$. Assessment of loco-regional lymph nodes has also been investigated extensively using different approaches, but more work needs to be done. Finally, evaluation of tumours during or after preoperative treatment is becoming an everyday reality. All these new aspects prompt a review of the most recent advances and opinions. In this review, a comprehensive overview of the current status of MRI in the
\end{abstract}

M. R. Torkzad

Section of Radiology, Department of Oncology, Radiology and Clinical Immunology, Uppsala University,

75185 Uppsala, Sweden

M. R. Torkzad $(\bowtie)$

Department of Radiology, Uppsala University Hospital, Uppsala, Sweden

e-mail: michael.torkzad@radiol.uu.se

L. Påhlman

Department of Surgery, Uppsala University Hospital,

Uppsala, Sweden

\section{B. Glimelius}

Department of Oncology, Radiology and Clinical Immunology,

Uppsala University, Uppsala,

Uppsala, Sweden

\section{B. Glimelius}

Department of Oncology and Pathology, Karolinska Institutet, Stockholm, Sweden loco-regional assessment and management of rectal cancer is presented. The findings on MRI and their accuracy are reviewed based on the most up-to-date evidence. Optimisation of MRI acquisition and relevant regional anatomy are also presented, based on published literature and our own experience.

Keywords MRI $\cdot \mathrm{CT} \cdot$ Rectum $\cdot$ Cancer

\section{Introduction}

Magnetic resonance imaging (MRI) has emerged as the dominant method of pelvic imaging in rectal cancer [1-4], although MRI is not always available [5]. The main reason for this dominance is the superb soft tissue contrast between tumour and other soft tissues on T2-weighted imaging on MRI, while computed tomography (CT) has difficulties in this regard [6]. MRI also provides the possibility of imaging in different planes, although multi-detector CT can also provide reformatted images.

Multi-disciplinary meetings using MRI have led to improved possibilities of selecting the most appropriate treatment for patients with rectal cancer [7-10]. Despite the apparent advantages, the value of MRI is sometimes overrated [11-13]. This is due to both misunderstandings as well as problems with application of the optimal protocol. In the Magnetic Resonance Imaging and Rectal Cancer European Equivalence Study (MERCURY), imaging workshops were held for participating radiologists to ensure standardisation of image acquisition techniques and interpretation of the images [14]. In this, the largest published study regarding the accuracy of staging of rectal cancer with the primary objective of assessing the depth of tumour extension in rectal cancer, T4-staging 
was done accurately in only five out of 14 cases [14]. One of the reasons for staging inaccuracies in everyday practice is probably the lack of imaging in the optimal plane [15-17]. One of the aforementioned studies [15] showed that among patients with a higher inaccuracy of staging, the number of sequences was higher and imaging was more commonly performed with gadolinium contrast enhancement.

The rectum has curvatures both in the right-left direction and in the antero-posterior direction. In addition, the rectum ampulla, as the name implies, especially when filled with a tumour/faeces has a spherical rather than a cylindrical shape and is thus more difficult to image perpendicular to its wall than if cylindrical. Finally, the pelvic floor is formed like a funnel necessitating different image planes than the three traditional orthogonal planes for adequate assessment. It can be difficult for nonspecialised MRI technicians to find a rectal tumour and to anticipate and plan the right imaging planes [18]. Good study quality, in addition to the inclusion of two interpreters, results in higher preoperative diagnostic precision [19].

The sensitivity and specificity of MRI in rectal tumours with regard to T-staging has also been shown to be dependent on the experience of the radiologist. In one study, the sensitivity and specificity of an expert radiologist were $96 \%$ and $74 \%$ respectively, while the same figures for a general radiologist were $77 \%$ and $40 \%$ [20].

In this review, we look in detail into the areas where MRI has improved patient care, and discuss the problem areas. Several suggestions are provided and areas where caution should be exercised are highlighted.

\section{Anatomical landmarks}

Rectum boundaries

The anal verge marks the lowermost portion of the anal canal and begins where the skin stops and where the anal mucosa (anoderm) starts [21]. The anal verge is best recognised in the sagittal plane (Fig. 1). It can be recognised as the lowermost portion of the anal sphincter complex. This can, however, be different on MRI compared with when the patient is examined by a surgeon who separates the buttocks.

The dentate line is located about $1.5-2 \mathrm{~cm}$ upwards from the anal verge. The dentate line is not visible on MRI, but occasionally the anal columns can be seen, the lowermost portion of which corresponds to the dentate line (Fig. 2) [22]. The dentate line corresponds approximately to the upper portion of the external sphincter muscle, which can be inferred on coronally oriented MRI.

The surgical anal canal extends about 3-4 cm, being shorter in women $(2-3 \mathrm{~cm})$, and ends at the anorectal ring or at the upper portion of the puborectal muscle. The puborectal muscle is the thicker portion of the pelvic floor musculature, and is less prominent in women than in men.

The inner muscular wall of the anal canal consists of the internal sphincter, which is the direct continuation of the circular layer of the muscularis propria of the rectum. The outer muscular wall of the anal canal is cranially composed of the puborectal muscle and caudally of the external sphincter [22].

The surgical rectum extends for $12-15 \mathrm{~cm}$ endoscopically from the anal verge. The length of the rectum is dependent on the size of the patients. In tall males the rectum can be 17$20 \mathrm{~cm}$ long and in women less than $15 \mathrm{~cm}$. The exact length

Fig. 1 Mid-sagittal plane turbo spin echo (TSE) image (a) $(1.5 \mathrm{~T})$ demonstrating lower part of the external sphincter merging toward the midline (arrows). The close-up TSE image (b) shows the anal verge (white line)

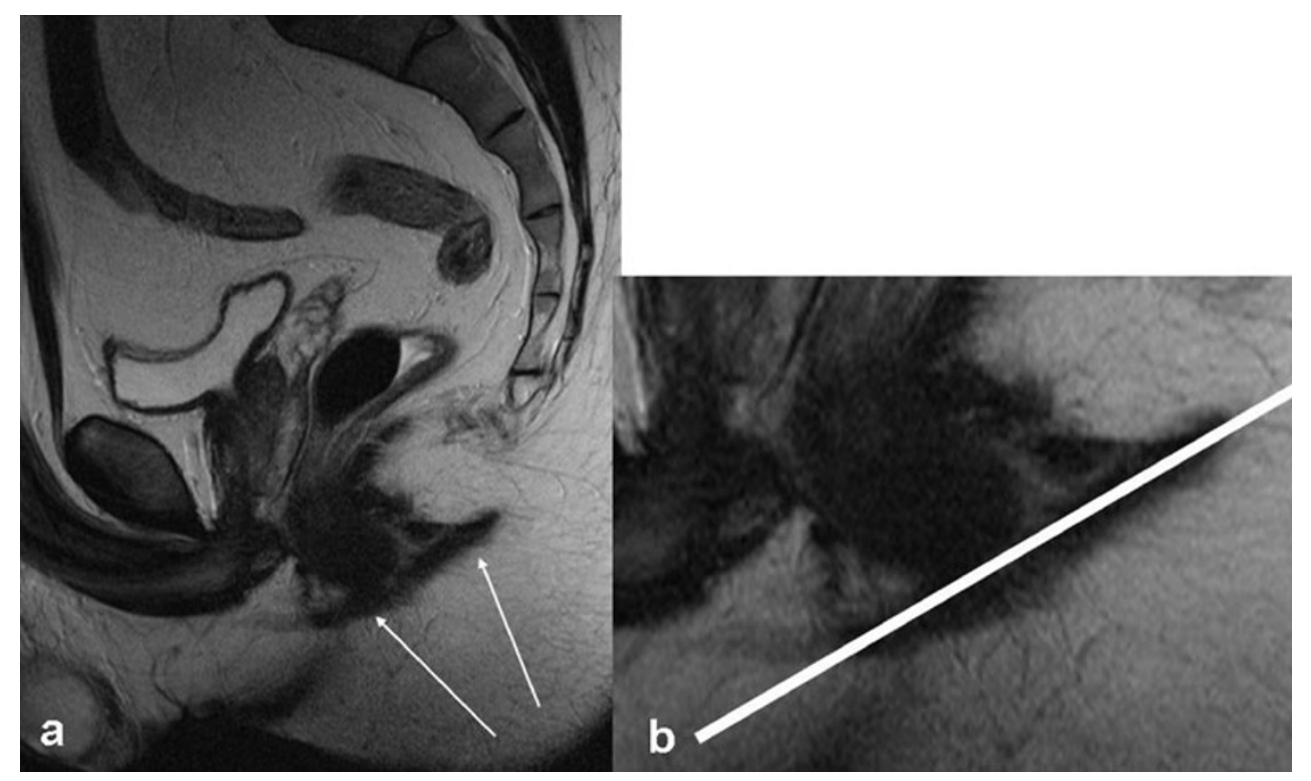




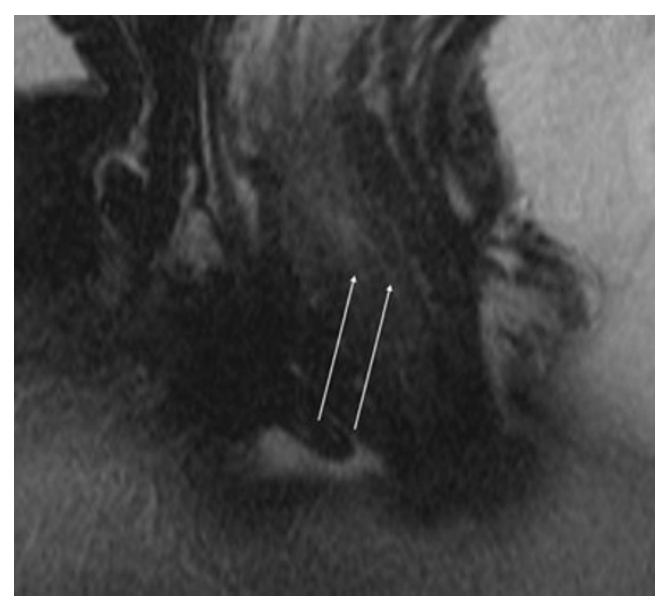

Fig. 2 TSE image (1.5 T) demonstrates alternating protruding mucosa and impressions corresponding to anal columns (white arrows)

can be evaluated best on the sagittal plane. However, for simplicity, $15 \mathrm{~cm}$ measured with a rigid sigmoidoscope has been used as standard. The anatomical definition of the rectosigmoid junction is based on haustrations. Haustrations are present in the sigmoid colon and absent in the rectum. In fact, "rectum" refers to the straight portion of the colon in the sense that the rectum lacks haustrations. Otherwise the rectum is much less straight than the name implies. In patients with diverticular disease of the sigmoid colon, this junction is appreciated more readily, as diverticula (more accurately referred to as pseudo-diverticula) denote sigmoid colon and not rectum. On high-resolution MRI, the rectosigmoid junction is the location where the rectum becomes completely covered by peritoneum. This is appreciated ventral to the rectum where the peritoneal reflection is detected. The rectosigmoid junction is orientated obliquely towards the sacrum. The peritoneal reflection is sometimes located more distally in women with a deep Douglas pouch, than in men [23]. In summary, the upper distinction of the rectum is $15 \mathrm{~cm}$ above the anal verge based on the rigid sigmoidoscope as most previous studies have used this definition. However, the radiologist should inform the members of the multidisciplinary team when a tumour originates from a mobile portion of the colon with a mesentery root, as this may be of relevance for the radiation target.

Surrounding the rectum, there is a layer of fat, the perirectal or the mesorectal fat. There is less fat anterior and caudal to the rectum than to the other sides [24]. The amount of perirectal fat is larger in men and correlates with the visceral compartment area, but not the body's cross-sectional area, body mass index or age [25]. Although the total amount of fat has not been shown to influence the accuracy of tumour staging [26], it is conceivable that the small distance between structures ventral to the rectum can make analysis of tumour growth assessment ventrally difficult [27]. The perirectal fat is often referred to as "mesorectum". The mesorectum is carpeted behind and laterally by a postero-lateral fibrous envelope belonging to the pelvic visceral fascia and ventrally by a recto-genital membrane of variable nature corresponding to "Denonvilliers' fascia" [28]. Denonvilliers' fascia covers the dorsal aspect of the prostate and seminal vesicles in men [29]. This fascia is fused to the mesorectal fascia as it concerns MRI. The mesorectal or perirectal visceral fascia (Fig. 3) has gained great importance as it pertains to rectal cancer surgery when total mesorectal excision (TME) was introduced. Tumours located close to this fascia are considered to threaten the fascia [30]. What constitutes a safe distance is, however, not
Fig. 3 Axial TSE image (a) $(1.5 \mathrm{~T})$ shows separation of the mesorectal fascia (white solid arrow), otherwise known as the perirectal visceral fascia, from the parietal pelvic fascia (dotted arrow). This is due to tumour in the upper portion of the uterosacral ligament (black arrow) shown on the higher axial TSE image (b)
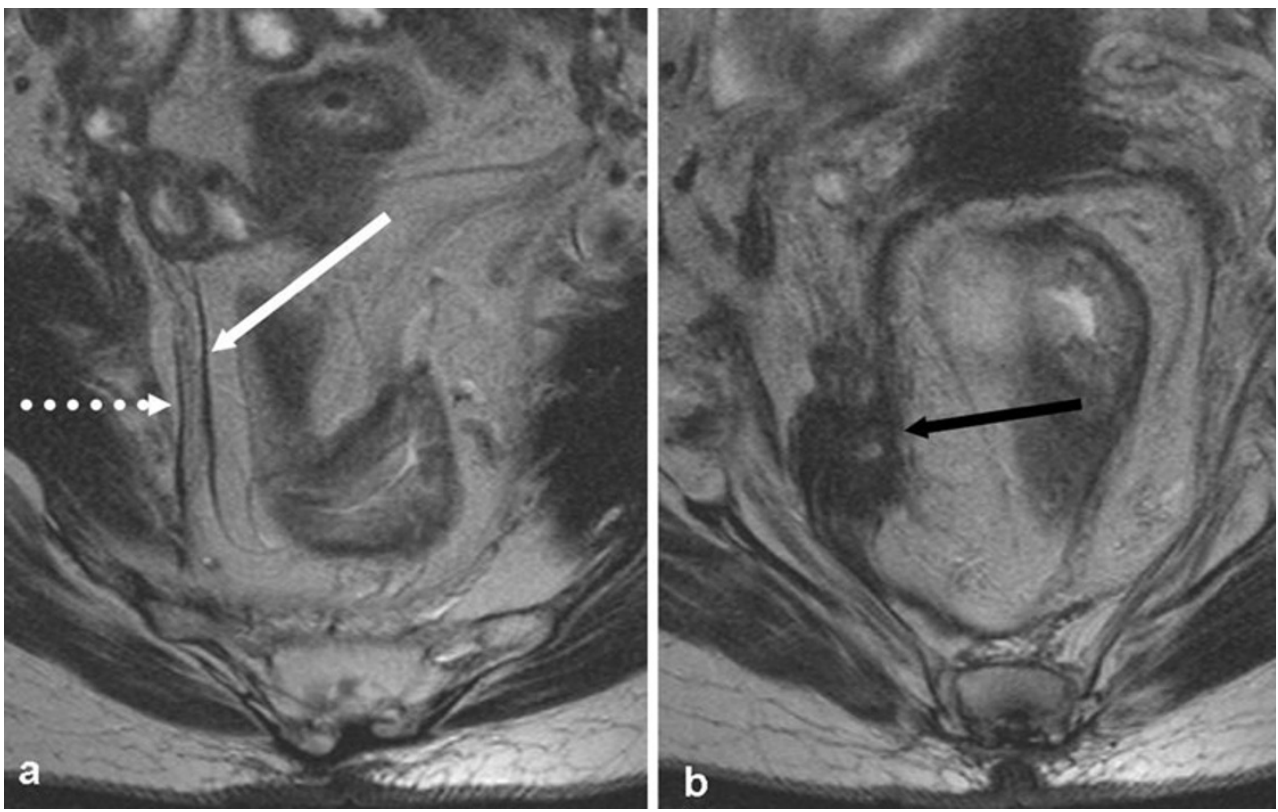
ascertained. A distance $<1 \mathrm{~mm}$ is definitely associated with risk of involvement of the surgical circumferential resection margin (CRM). Distance $<2-5 \mathrm{~mm}$ has also been suggested as indicative of a threatened margin with a greater risk of recurrence. Obviously, the larger the safe margin the less likelihood of false-negative results, however at the expense of low specificity. Also, adopting a larger safe margin would lead to classifying most anterior and low tumours as potentially threatening the fascia. At most centres, $1 \mathrm{~mm}$ is considered the safe distance. Care should be exercised not to confuse the CRM and mesorectal fascia with one another. CRM is a surgical term and can be intentionally or inadvertently inside or outside the mesorectal fascia.

What the surgeon and/or oncologist need(s) to know

For optimal preoperative treatment planning of rectal cancer, adequate local staging is of paramount importance [30]. Factors associated with prognosis are tumour height, T-stage, extramural tumour growth, lymph node status, vascular and neural invasion, threatened CRM and overgrowth to adjacent structures. In addition, narrow obstetric conjugate and shorter interspinous distance appear to be factors leading to poor surgical quality [31].

There are differences in how surgeons, oncologists and therapeutic radiologists treat patients. There is growing support for treatments being employed before surgery as opposed to after surgery. The former has been employed in Europe for some time now, and it seems to be becoming the dominant approach even in the US. At our institution, postoperative treatment is mostly part of salvation therapy, given only very rarely. In Europe tumours are generally divided into three categories based on radiological findings into "good" (those with the best prognosis and therefore no need for preoperative neoadjuvant therapy), "bad" (tumours that require only short-term preoperative neoadjuvant therapy) and "ugly" (tumours in need of more extensive preoperative neoadjuvant therapy). There are some minor differences between different institutions as to what constitutes good, bad or ugly, but most authors consider T1-2 N0 tumours as good and any tumour threatening/involving the mesorectal fascia or T4 as ugly. The areas of differences are the following:

- N1 tumours are considered sometimes by some authors as part of the good group, and by others as a sign of the bad group. If a malignant lymph node threatens the mesorectal fascia, however, the classification should be ugly.

- Signs of vessel invasion have been used for up-front chemotherapy by some or classification as a sign of the bad group by others.

- Some consider small T3 tumours (T3a, or T3a-b) as good.
Below, the most important of these factors will be discussed. Before reading the following sections, we would like to emphasise two points:

First, one should avoid staging for lesions that are not definitely cancers. T-staging is only for adenocarcinomas and not benign polyps or other tumours. While experienced clinicians might discover this, inexperienced clinicians in cases of inadequate biopsies might not understand the limitations of MRI and consequently make a diagnosis of cancer.

Second, for anal cancers (squamous cell carcinomas) the staging system is completely different from that of low rectal tumours. The same applies to metastases from other primaries to the rectum. There are some clues to differentiate rectal cancers from other tumours. Discussion of these signs is beyond the scope of this article; however, calcification, mucin production, circumferential growth and mucosa ulceration are more commonly seen in adenocarcinomas than in other malignancies.

\section{T-stage}

T-staging is based on the tumour relationship to the muscularis propria layer, and invasion of neighbouring organs. The muscularis propria is demonstrated as a thin lower signal layer surrounding the rectum (Fig. 4).

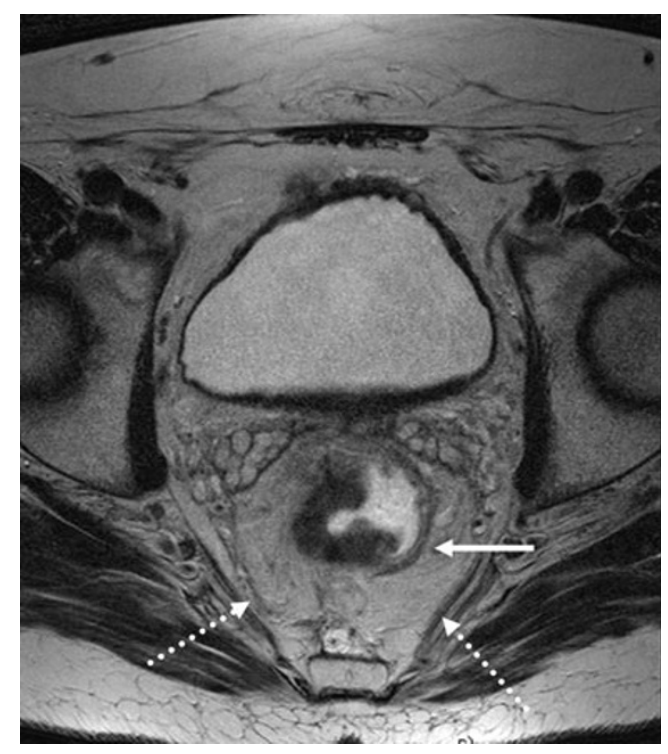

Fig. 4 Axial TSE image $(1.5 \mathrm{~T})$ of the pelvis at the level of a midrectal cancer. The intact muscularis propria is seen as a thin dark band on the left side where no tumour is present (solid arrow). The mesorectal fascia is also marked by the dotted arrows. Both the muscularis propria and the mesorectal fascia are visible as a thin lowsignal layer and line, respectively. However the imaging plane should meet these structures perpendicularly for optimal demonstration 
T-staging in rectal cancer [according to UICC (International Union Against Cancer) TNM5] is classified in the following manner:

TX: not determined

T0: no visible tumour

Tis: carcinoma in situ

T1: submucosal tumour only (Fig. 5)

$\mathrm{T} 2$ : growth into the muscularis propria.

T3: growth into the perirectal fat

T4: growth into neighbouring organs, or perforation (Fig. 6)

- (a) Other organs, excluding peritoneum

- (b) Peritoneum (T4 a and T4b are reversed in TNM versions 6 and 7)

If the radiologist intends to use TNM staging, it is important that the clinicians and the radiologist have an understanding of which version of TNM is employed. Clearly, the TNM staging system is lagging behind on several grounds [32], including what constitutes neighbouring "organ" structures. The major pelvic vessels, the pelvic parietal fascia (the fascia covering lateral extraperitoneal structures mainly consisting of major pelvic vessels) and the mesorectal fascia are not considered "organs". The status of the pelvic floor musculature is not explicitly mentioned as neighbouring organs. Therefore, care should be taken to convey the information to clinicians in the most appropriate manner. Another issue that might be confusing to a radiologist is that a rectal cancer can grow into a structure covered by peritoneum, such as the small bowel or corpus uteri, without actually involving the peritoneum.

Most studies have concentrated on T-staging accuracy with moderate-good results [33]. The problem with these studies, however, is that they mostly include T2 and T3 cases and relatively few $\mathrm{T} 4$ and $\mathrm{T} 1$ cases. The reported total MRI diagnostic accuracy is $66-88 \%[6,11,13,15,21,26$, 30, 34-36].

In order to have the best assessment of T-staging and particularly the distinction among T1, T2 and "early" T3, the plane of imaging should be perpendicular to the muscular layer at the location of the largest tumour burden in order to overcome problems with partial volume effect. This may not be necessary with large T3 tumours, unless these tumours are closer to the mesorectal fascia at a location other than where they have the largest tumour extension. In these cases, assessment of mesorectal fascia takes precedence and should be evaluated with the appropriate plane of imaging. Our experience from studies with a total of more than 900 cases with histopathological information is that several signs should alert the radiologist to look more intensively for extramural tumour growth (T3) when the following are present:

- Tumour ulceration

- Tumour larger than semi-circumferential

- Long tumours

- Malignant lymph nodes

- Distant metastases

Tumours tend to extend beyond the muscular layer at their centre, both in the longitudinal plane, parallel to the rectum, and in the plane perpendicular to the rectum. This rule does have exceptions. Some tumours, especially large ones and mucin-producing tumours, can extend through the muscularis propria at several locations.

For adequate assessment of tumour growth into neighbouring structures and organs, imaging should be done in the plane that demonstrates the smallest distance between the tumour, on the one hand, and the neighbouring organ and/or the mesorectal fascia, on the other hand. Demonstration of fat between the tumour and neighbouring
Fig. 5 True transversal TSE image of the pelvis (a) $(1.5 \mathrm{~T})$ demonstrates a small tumour (arrow). High-resolution TSE image with thin slice $(3 \mathrm{~mm})$ perpendicular to the muscular wall (black arrow) shows a $\mathrm{T} 1$ tumour (b)
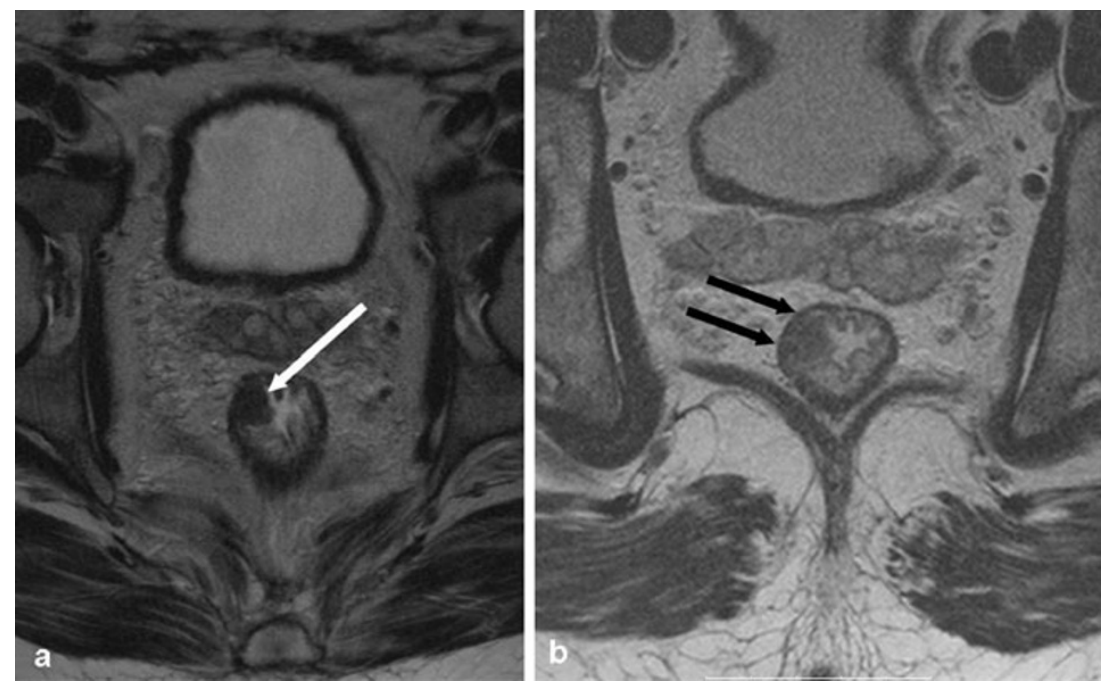
Fig. 6 Axial (a) and sagittal (b) plane reformatted images from original sagittal threedimensional (3D) T2-weighted images $(3 \mathrm{~T})$ show a rectal cancer (white arrow) growing into an adjacent small bowel loop
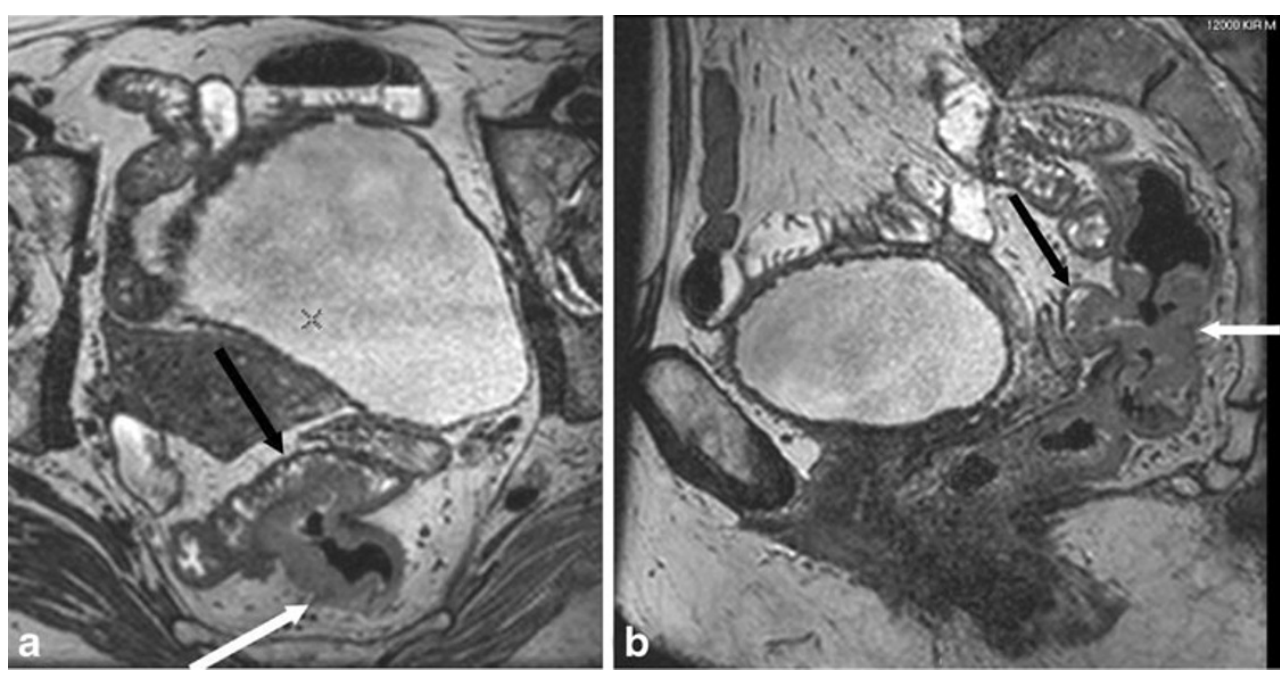

structures is evidence of non-involvement. Absence of fat, however, does not necessarily indicate tumour invasion. If nearly simultaneous or later CT of the pelvis is obtained, it is prudent to study the $\mathrm{CT}$ as well. It is not infrequently seen that a structure lying close to the tumour with virtually no intervening fat on MRI, is seen separated from the tumour by fat on CT. The best signs for growth of rectal cancer into neighbouring organs are nodular growth into the neighbouring organ or causing obstruction (e.g. hydronephrosis) [15]. Retraction of fasciae is considered a sign of tumour growth by some authors, yet it does come with exceptions.

Tumour perforation is classified as $\mathrm{T} 4$ according to the TNM classification. Abscesses are usually limited by the mesorectal fascia.

Small tumour spiculations can contain tumour cells. Tumours have a tendency to grow along fasciae and nerves stretching to other structures not primarily close to the tumour (Fig. 7). Tumours with high mucin content can also cause problems. Occasionally, mucin fills out and replaces the whole mesorectal fat. On T2 weighted imaging,

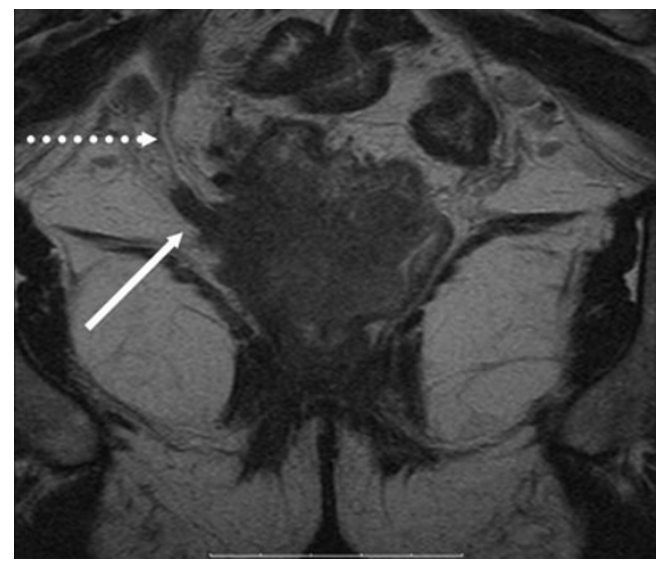

Fig. 7 Semi-coronal plane TSE image (1.5 T) showing tumour (solid arrow) growing along the side mesorectal fascia (dotted arrow) especially with shorter echo time (TE), the contrast between the fluid-like signal of the mucin and fat could be lost (Fig. 8). In our experience, T1-weighted imaging, simultaneous CT or great experience of the radiologist can overcome this problem. Another solution could be higher TE with TSE images, which leads to larger T2 weighting and thus makes mucin appear brighter than fat (Fig. 8). It is, therefore, wise to have one plane of imaging with higher TE.

\section{Distance to the mesorectal fascia}

The distance to the mesorectal fascia is the single most important local prognostic factor. When the distance on preoperative MRI is small, the risk of involved CRM is increased considerably [33]. It has been suggested that by applying MRI for the selection of whether preoperative treatment should be given or not before optimal surgery, the frequency of neo-adjuvant treatment, with its acute and late adverse effects, can be as low as $30-35 \%$ without reduction of pathologically CRM-negative resection specimens [37]. CRM positivity conveys a great risk of both local and distant failure, being the relevant clinical endpoints. However, it has been shown that the greatest relative effects of preoperative radiotherapy are when the distance to the CRM is the greatest [38]. As mentioned above, what constitutes a threatened margin has been the subject of several studies and the lower the threshold, the higher the sensitivity at the cost of specificity. At most centres, a margin of $1 \mathrm{~mm}$ is considered the threshold, yet others have chosen other thresholds [39-41]. In order to obtain the best results both the imaging plane and the slice thickness of the imaging on T2-weighted imaging should be optimised in the same way as when involvement of other neighbouring structures is studied. In the MERCURY study, $93 \%$ of the studies were technically satisfactory and among these, the 
Fig. 8 Axial (a) and semi-axial (b) TSE images $(1.5 \mathrm{~T})$ of a mucin-producing tumour. The first image (a) with higher TE $(120 \mathrm{~ms})$ produces a stark contrast between fluid/mucin (stars) and fat. Both the urine in the urinary bladder (large star) and the tumour mucin (small star) have higher signal than the surrounding fat. The urinary bladder was emptied and the patient imaged with lower TE $(80 \mathrm{~ms})$. There is very little contrast between mucin and fat, or between urine and fat
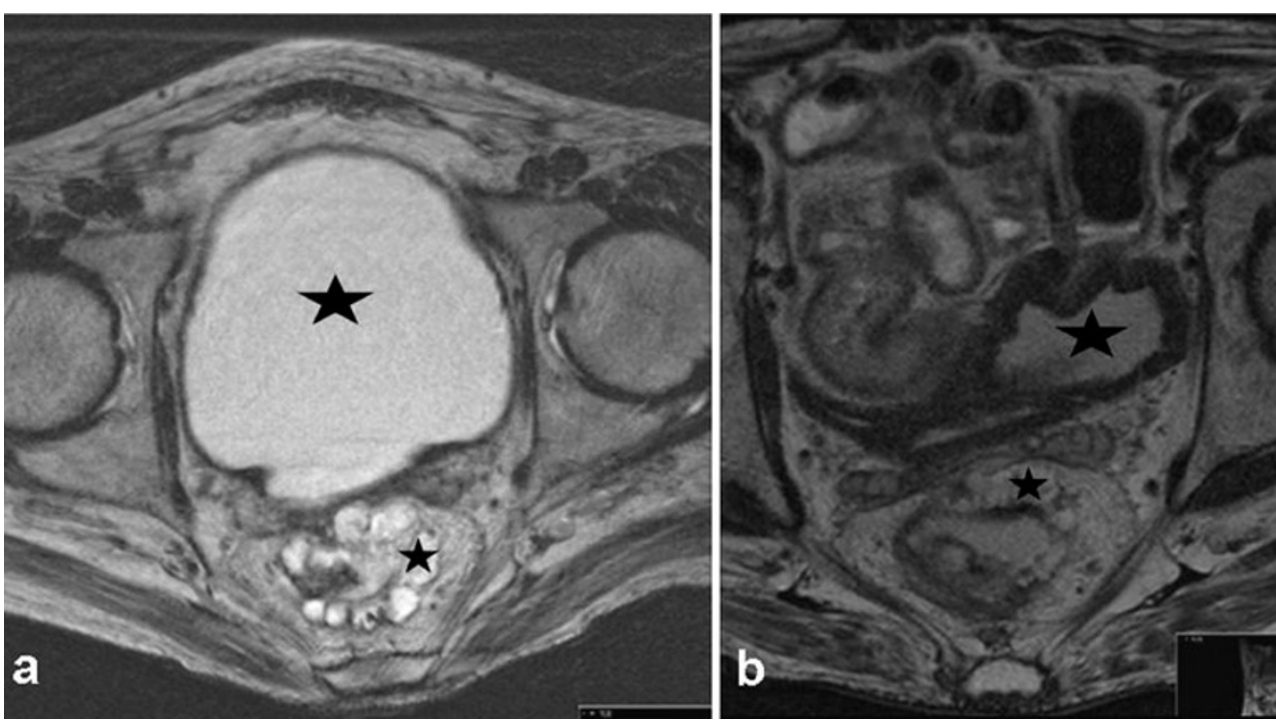

specificity for prediction of a clear margin was $92 \%$ [14, 42]. Others have reported an accuracy rate of $88 \%$ [43]. Ability to assess the potential endangerment of the mesorectal fascia has been the most important prognostic indicator. As the mesorectal fascia is very thin, it is mandatory to have an imaging plane perpendicular to this fascia in case of possible tumour encroachment. Once again, we would like to emphasise that what the radiologist evaluates is threatening or involvement of the mesorectal fascia. Involvement of the CRM is decided at surgery, because the CRM is defined after surgery.

Interestingly, both $T 1$-weighted images and $C T$ can give the same information in locations where there is enough fat between the rectum and the mesorectal fascia as long as we can differentiate between the tumour and the rectal wall based on other information. This is due to the fact that both T1-weighted images and $\mathrm{CT}$ provide excellent contrast between tumour tissue/mesorectal fascia and fat. It is perhaps not surprising that low and anterior rectal tumours are associated with overestimation of the involvement of the mesorectal fascia on MRI [27]. One should, however, note that the least distance between the tumour and the mesorectal fascia is measured at points where the tumour extends beyond the muscularis layer. Therefore, $\mathrm{T} 1$ and $\mathrm{T} 2$ tumours do not have threatened resection margins per definition, except in the anal canal. Moreover, the distance between T3 tumours and the fascia should be measured at the location where the tumour extends outside the muscular propria layer as mentioned above. Pushing of neighbouring organs and proximity are unspecific signs of tumour overgrowth.

Administration of rectal enema can affect the distance between the tumour and the mesorectal fascia [44], yet there are no studies that have looked at whether assessment of CRM status (threatened/involved or not) is influenced. In CT colonography, sufficient filling of the rectum can lead to effacement of the rectal wall and mesorectal fascia. This could mean that the distance to the mesorectal fascia is not fixed but variable to some extent. Large polypoid luminal tumours can often expand the rectum and can infrequently not be diagnosed as threatening the fascia or even classified as $\mathrm{T} 4$ tumours.

\section{N-stage}

The presence of malignant lymph nodes adversely affects the prognosis. Generally, in gastrointestinal tumours Nstage is not influenced by the location of lymph nodes but mainly by the number of regional metastatic lymph nodes. For rectal cancer, one to three malignant nodes in the perirectal fat denote $\mathrm{N} 1$ stage, while more than three malignant nodes denote $\mathrm{N} 2$ stage. These classifications have been modified in TNM7, with subclasses defined based on smaller subgroups with a different number of malignant nodes. $\mathrm{N} 1$ is still metastasis in one to three regional lymph nodes, with N1a metastasis to one node, $\mathrm{N} 1 \mathrm{~b}$ metastasis to two to three nodes, and N1c is metastatic satellites in subserosa, without recognisable nodal structures. N2 is metastasis in four or more regional lymph nodes, with N2a in four to six nodes and N2b in seven or more. We still apply TNM version 5 at our centre, yet it would be prudent for radiologists to try to provide the number of nodes they deem malignant so that confusion is avoided.

Many studies have looked at whether MRI can detect the presence of lymph node metastasis (N0 vs other $\mathrm{N}$-stages). These studies, based primarily on lymph node size, have not shown very high accuracy rates (70-76\%) for the diagnosis of presence of malignant lymph nodes [45-48].

During the past decade the attention in the radiology literature has shifted towards the appearance of individual 
nodes. Some cancers, such as rectal and prostate cancers, tend to have infiltrative lymph node metastasis. In these patients the malignant nodes do not enlarge early on and in fact most malignant nodes are small in rectal cancer. Several studies have looked at the contour and homogeneity of the lymph nodes $[49,50]$. Despite promising initial results, probably due to assessments of only larger nodes, later studies have failed to replicate the same success [51]. Node calcification, seen best on CT, should be interpreted as carrying a high risk of malignancy in the setting of rectal cancer, just like calcification anywhere else. Gadolinium has also been used for lymph node staging, although the accuracy rates have similarly been around $70 \%$ [52]. There are no studies that have combined the pattern of gadolinium enhancement and lymph node morphology to see if lymph nodes assessment is improved.

More recently, several studies have focused on ultrasmall superparamagnetic iron oxide (USPIO) particles with promising results [53]. The mechanism of action is uptake of USPIO by scavenger cells present in normal lymph nodes. This leads to loss of signal on T2- and especially T2*-weighted imaging. Nodes with malignancy replacing normal cells are not affected. The estimated percentage of the white region (i.e. areas without loss of signal, and therefore no uptake of USPIO) and measured ratio are the most accurate and most practical criteria for predicting malignant nodes [54]. Despite promising results, the Food and Drug Administration (FDA) of the United States has not approved the application for routine clinical use, and consequently the manufacturer has withdrawn its application to the European Medicines Agency. This places some serious doubt on the future of this agent. Furthermore, USPIO requires administration the day before, with imaging the following day. Also, image interpretation demands a learning curve. This could mean that, even if approved, there might be some time before this agent, if ever, is widely used in Europe or the US.

Diffusion-weighted imaging (DWI) has been suggested as a method for the assessment of malignancy in lymph nodes. DWI shows differences between tumour tissue and non-malignant tissue because of higher cell density in malignancies. However, there is a great degree of overlap between malignant and benign nodes; therefore, the clinical implications of DWI are at present unclear. In gynaecological tumours, the diffusion-perfusion fraction or correlating apparent diffusion coefficients (ADC) of the nodes with the ADC of the tumour as an adjunct to the size criteria has improved lymph node staging. This approach has not been used for rectal cancer yet, nor has it been validated by more studies for gynaecological tumours. More on diffusion can be found later in this article [55].

New hope is emerging for ultra-thin T2-weighted imaging (Fig. 9). Studies using this method are ongoing at our centre with initial promising results. The basis of this method is basically the same as above regarding lymph node morphology. We have been able to assess even smaller nodes using the same criteria and find malignant nodes with more confidence. It is not known if the diagnostic accuracy regarding $\mathrm{N}$-staging will significantly increase.

Another potentially promising approach could be specific intravascular contrast agent bound to albumin. This contrast agent seems to be limited to normal vessels and not the abnormal vasculature of a malignant tumour. There is hope that this agent might help distinguish areas of focal chronic pancreatitis from pancreas cancer. Moreover, this agent has been used in ten patients and has shown enhancement of normal lymph nodes or non-tumourinvolved parts of the lymph nodes [56].

Fig. 9 Tumour (solid arrow) in the upper rectum shown on traditional TSE on sagittal plane (a) and thin-slice 3D T2weighted sagittal image (b) both on $3 \mathrm{~T}$ MRI. The anterior lymph node (hatched) is more clearly depicted on the thinner slice $(1 \mathrm{~mm})$. Additionally, one can see that this node is irregular in contour and involves the peritoneum (dotted arrows) behind the uterus

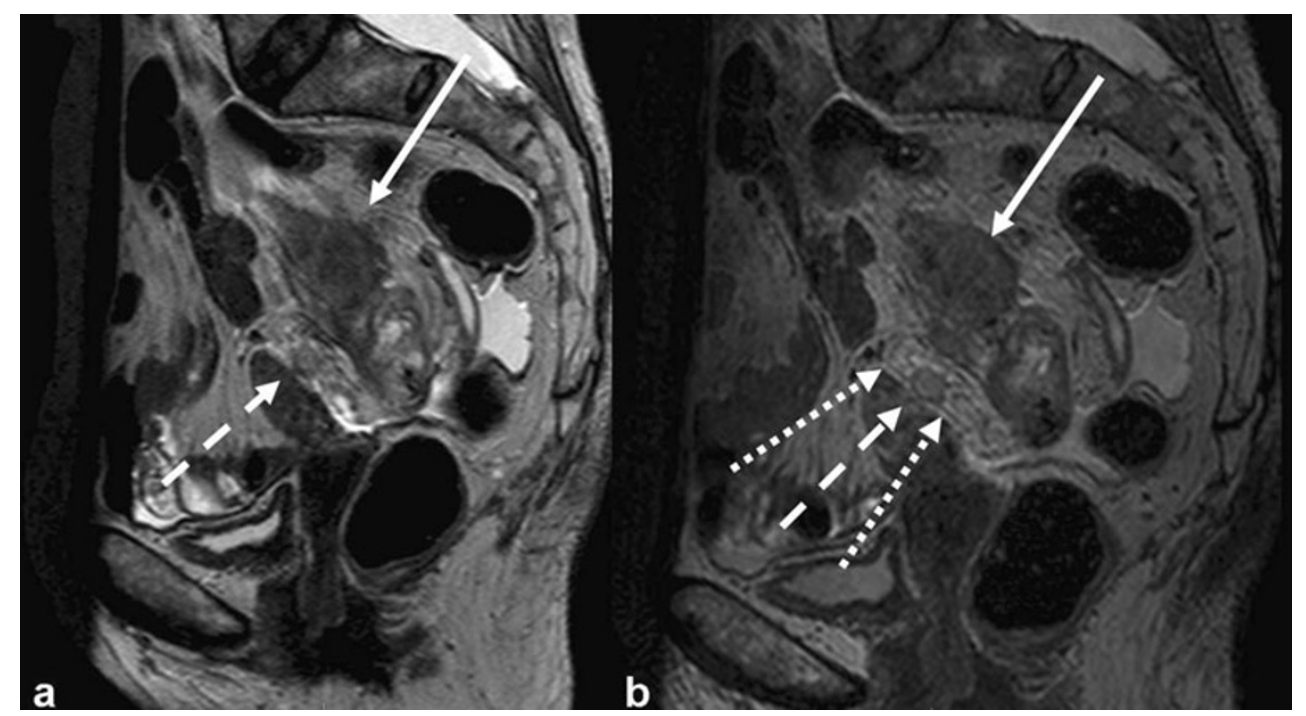


Whatever method used, one has to remember that a lymph node is a complex structure and malignancy in a lymph node does not always uniformly change the node. A lymph node can harbour micrometastasis or minimetastasis. Lymph node involvement can be patchy. Another important issue is that not all malignant mesorectal lymph nodes have the same prognostic importance. As outlined above, subserosal metastases are prognostically more important than up to three malignant mesorectal lymph nodes according to TNM7. Also, a malignant lymph node deep inside the mesorectal fascia will not adversely affect surgical outcome as much a malignant lymph node lying on the mesorectal fascia could because the latter could potentially threaten the fascia and consequently the CRM.

Most nodes in patients with rectal cancer are located in the laterodorsal part of the mesorectum, with no difference in distribution between malignant and benign nodes. The majority of positive nodes are located at the level of the tumour or above it. There are significantly more benign nodes located below the tumour than malignant nodes. Low rectal or anorectal tumours are at potential risk of metastasising to the pelvic side walls and occasionally inguinal lymph nodes [57], yet embryology does not always dictate metastatic pathways [58].

There is some controversy regarding how to handle metastatic lymph nodes in the pelvic side walls. In Japan, removal of these nodes is considered essential in the curative treatment of selected patients, whereas in Western
Europe these sites are covered by radiation. In Western Europe, involved nodes are generally considered as signs of distant metastatic disease [59-61], at least in tumours above the peritoneal recess. Not infrequently, we see malignant lateral pelvic lymph nodes clearly along the drainage of the middle rectal and obturator vessels. Malignancy in the lateral pelvic nodes in the absence of a low locally advanced rectal cancer should lead to a search for other malignancies (e.g. prostate, Fig. 10).

We are still a long way from the accurate assessment of lymph nodes. Many patients receive preoperative treatment making the correlation between MRI before treatment and histopathology rarely possible. Suspected lymph node metastases are a strong indication for preoperative treatment. Moreover, we need to know that we are correlating the correct lymph nodes. This is particularly important for a lymph node close to the resection margin. If a node lying close to a future resection margin is malignant, the treatment strategy could be greatly influenced. Also, very small lymph nodes can be malignant nodes that we might not even be able to detect with at least some of the methods mentioned above. Finally, a lymph node completely replaced by tumour or mucin could cause interpretation problems for the pathologist. Most pathologists wish to see some remaining lymph node tissue to distinguish a malignant lymph node from an extramural metastasis. This has caused controversies in proper Nstaging and also influenced the definitions in the TNM systems [62].
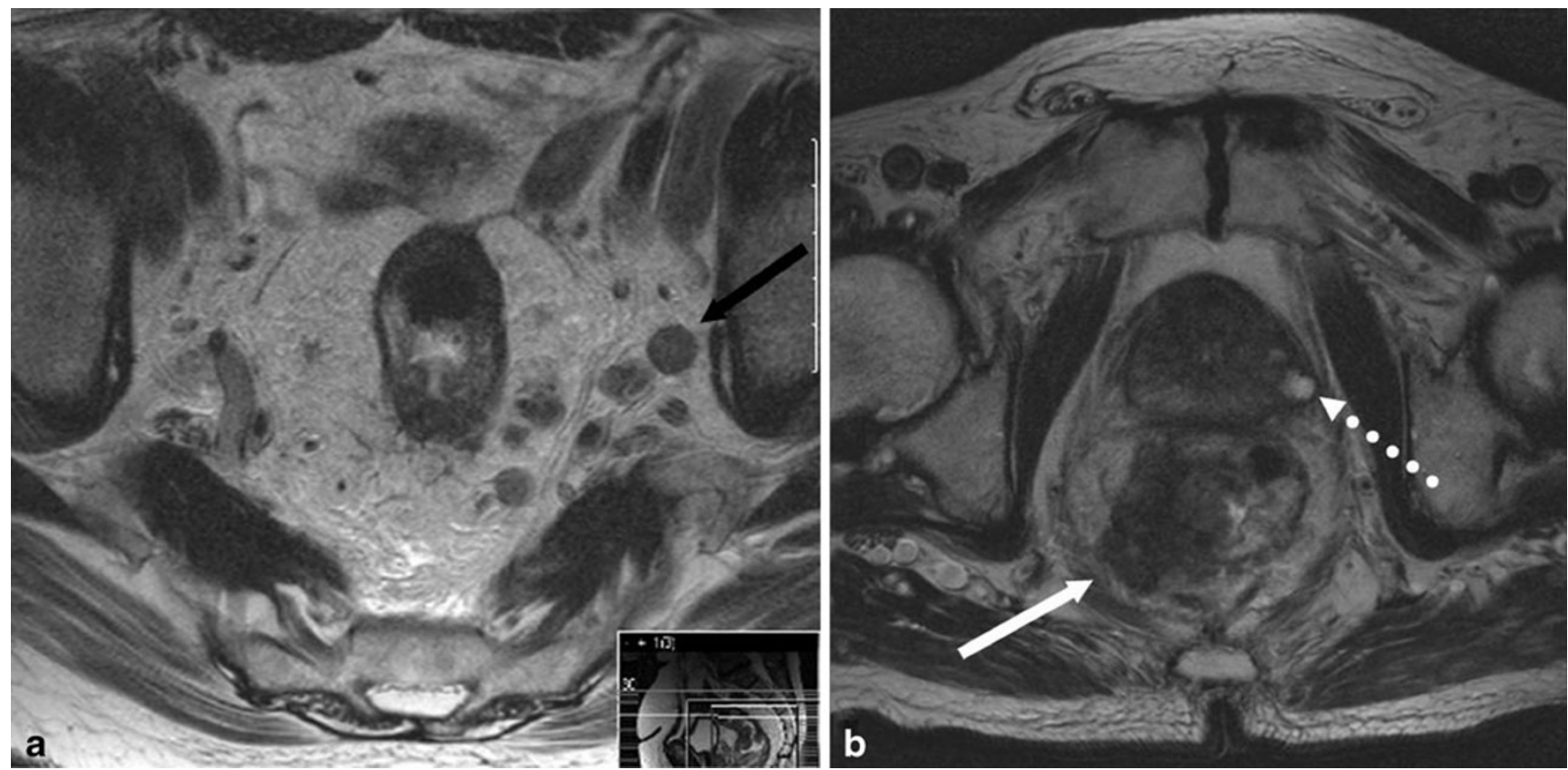

Fig. 10 Axial TSE images (1.5 T) of a rectal cancer originating from the right rectal wall (white arrow). There is a malignant lymph node (black arrow) in the obturator fossa on the left side. The cause of the malignant lymph node is the prostate cancer (dotted arrow) 


\section{Tumour height and tumour size}

The tumour height is measured from the anal verge up until the lowermost portion of the tumour shows attachment to the wall. On MRI, the distance is measured on a line drawn on the sagittal plane. This distance could be different from the one measured on a straight rigid rectoscope, but in our experience the difference is seldom larger than $1 \mathrm{~cm}$. Tumour height defines if a tumour is a rectal cancer or a sigmoid cancer. The limit used for this purpose varies between countries from 10 to $15 \mathrm{~cm}$. In the axial plane, the rectum finishes below the S1-2 disc [24, 26]. Coincidentally the upper limit of what constitutes the rectum (i.e. $15 \mathrm{~cm}$ from the anal verge) in Western Europe is the largest surgical definition of the rectum that we know of.

A tumour that begins within 5-6 cm of the anal verge is considered a low rectal cancer and is associated with a higher risk of recurrence [39, 63]. Low rectal tumours can be difficult to assess on MRI and, therefore, a novel staging system for these tumours is suggested (Fig. 11) [64]. This classification is based on the fact that tumours growing into or beyond the intersphincteric plane on MRI have a higher likelihood of positive CRM even after preoperative treatment [65]. The more simplified approach could improve reproducibility.

For assessment of tumour size, the best single variable is the length of the tumour [66]. Measuring tumour volume offers better correlation with histopathology than tumour length; however, volume measurement is more cumbersome. Tumour diameters are subject to more variation than tumour volume. When measuring tumours, one should remember that the luminal polypoid part of the tumour is prone to slough off, especially after treatment. It is not uncommon that these tumours are initially over-staged as
$\mathrm{T} 3$ or T4 because of expansion of the rectum and problems with imaging. After preoperative treatment, the limited growth of these tumours is seen because of the sloughed luminal portion. To assess the extramural growth of these tumours, one should focus on the pedicle and the extramural portions of the tumours.

\section{Neurovascular invasion}

Extension along nerves and extramural intravascular growth are associated with a worse prognosis. Extension along nerves, especially tiny neural branches, is not easily seen on MRI. We have occasionally seen tumour extensions in the form of thick nodular bands extending towards the sacral neural foramina or lumbosacral nerves. Extension along the lateral mesorectal fascia close to hypogastric nerves should raise suspicion of neural growth.

Intravascular extension is, however, easier for the radiologist to diagnose (Fig. 12). Tumours usually grow along vessels. However, this perivascular growth is not always equal to intravascular growth. A new system has been proposed for the assessment of intravascular growth $[67,68]$. According to this scoring system for intravascular growth assessment, the more signs present the higher likelihood of intravascular growth. These signs are nodular growth at the site of extramural growth, vessel in proximity to the tumour, vascular enlargement and vessel signal heterogeneity. The authors of the mentioned studies have found that when more than two signs are present, the prognosis is similar to when tumours have intravascular growth histopathologically.

Imaging with $3 \mathrm{~T}$ and variable flip angle ultra-thin 3D makes the distinction of vessels easier because of infinite ET leading to normal vessels having a more homogeneous

Fig. 11 Coronal images of two low rectal tumours. In one case (a, reformatted from original sagittal 3D T2-weighted image, $3 \mathrm{~T}$ ), the tumour obliterates the intervening fat (black arrow) between the pelvic floor and the rectal lumen. In the other case (b, TSE image, 1.5 T), the intervening fat is preserved (white arrow)
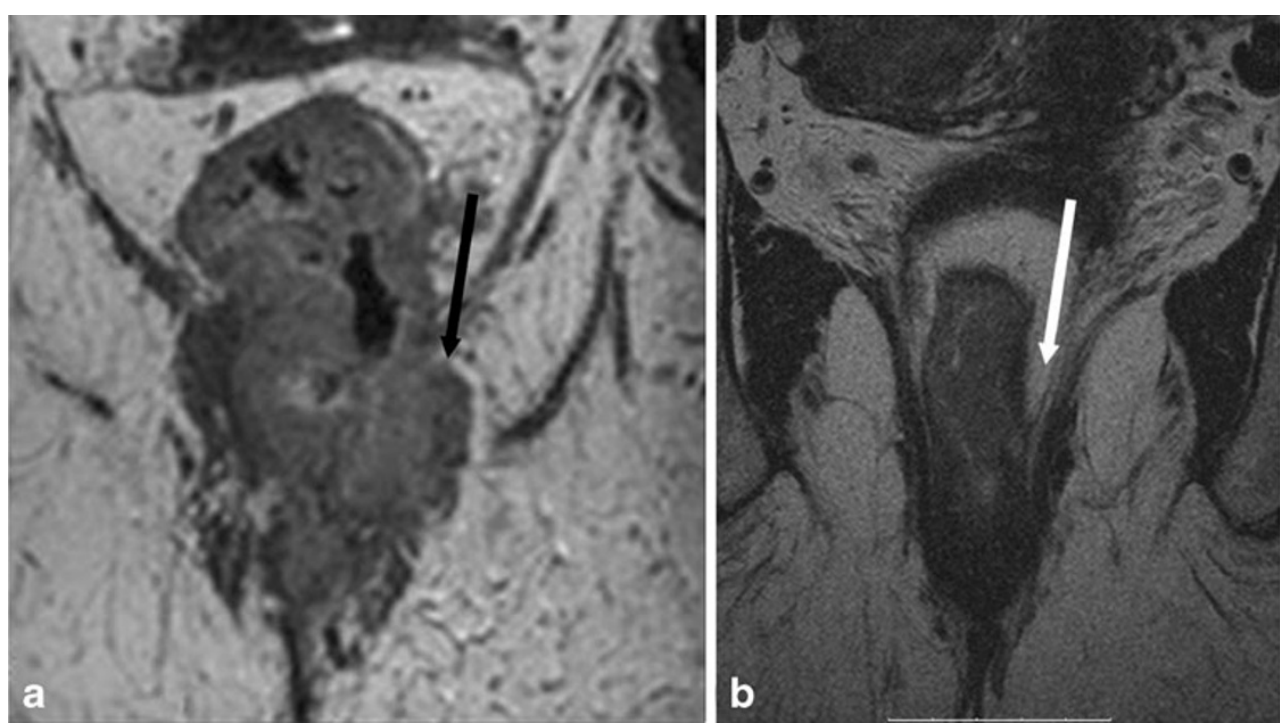


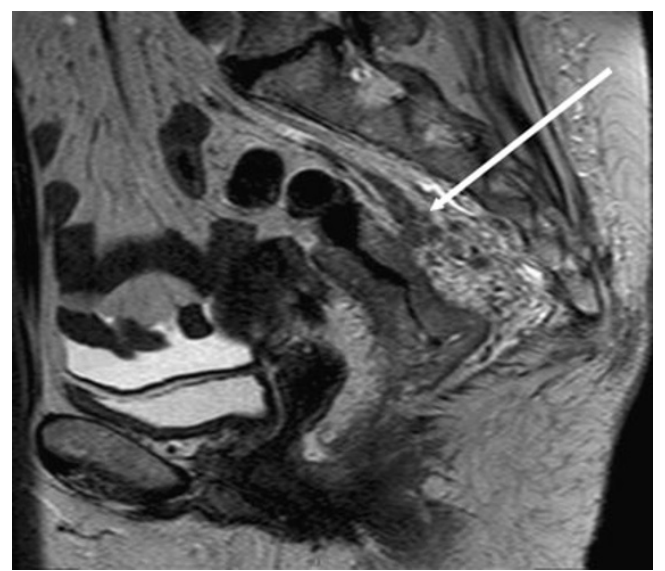

Fig. 12 Sagittal plane TSE image (3 T) showing rectal tumour with intravascular growth (arrow). The vessel is expanded, irregular, showing tumour signal and is close to the tumour

signal pattern. The extension through the muscular propria appears to occur predominantly where the vessels enter the rectum, a location where the muscular coat is also absent.

\section{Extramural tumour growth or depth}

Extramural depth (EMD) is the tumour extension into the mesorectal fat in $\mathrm{T} 3$ tumours. It is measured in millimetres on a line perpendicular to the rectum. A classification system has been adopted at several centres based on the extension of EMD outside the muscular layer. T3a is a T3 tumour with EMD $<1 \mathrm{~mm}, \mathrm{~T} 3 \mathrm{~b} \geq 1 \mathrm{~mm}$ and $<5 \mathrm{~mm}, \mathrm{~T} 3 \mathrm{c} \geq 5 \mathrm{~mm}$ and
$<15 \mathrm{~mm}$, and $\mathrm{T} 3 \mathrm{~d} \geq 15 \mathrm{~mm}$. The same system is also used for colon cancer.

The MERCURY study [14] showed that MRI provides a non-biased estimation of EMD, the latter being an important prognostic factor [69]. The 95\% range of over- and underestimation of EMD was about 4-5 mm compared with histopathology [70, 71]. It is possible that the figure of $4 \mathrm{~mm}$ is a reflection of slice thickness [72]. Another smaller study has also demonstrated good correspondence between histopathology and MRI for measurement of EMD (Fig. 13) [73].

Of all patients with rectal cancer who undergo preoperative MRI staging, about half will have features indicating a good prognosis (T1-T3a-b, N0, no vascular invasion, clear CRM) and may safely undergo primary TME [4, 39], although others advocate neo-adjuvant therapy for all T3N0 tumours [74]. Nevertheless, the decision to give neo-adjuvant therapy can be decided based on EMD, provided there is no endangerment of the mesorectal fascia or nearby organs, and if there are no malignant lymph nodes or signs of intravascular growth. This places great pressure on the radiologist to ascertain the exact EMD in T3 tumours. As mentioned above, $95 \%$ of the results in the MERCURY study were within 4-5 mm of the histopathological measurements. If the multidisciplinary team wants to base the decision to administer preoperative therapy based on EMD, then he/she must take into account the possibility of some $\mathrm{T} 3 \mathrm{a}$ and $\mathrm{T} 3 \mathrm{~b}$ tumours being misclassified as $\mathrm{T} 3 \mathrm{c}$ and vice versa. To solely rely on EMD is not correct, as other factors like tumour height from the anal verge, whether the tumour is anterior, lateral
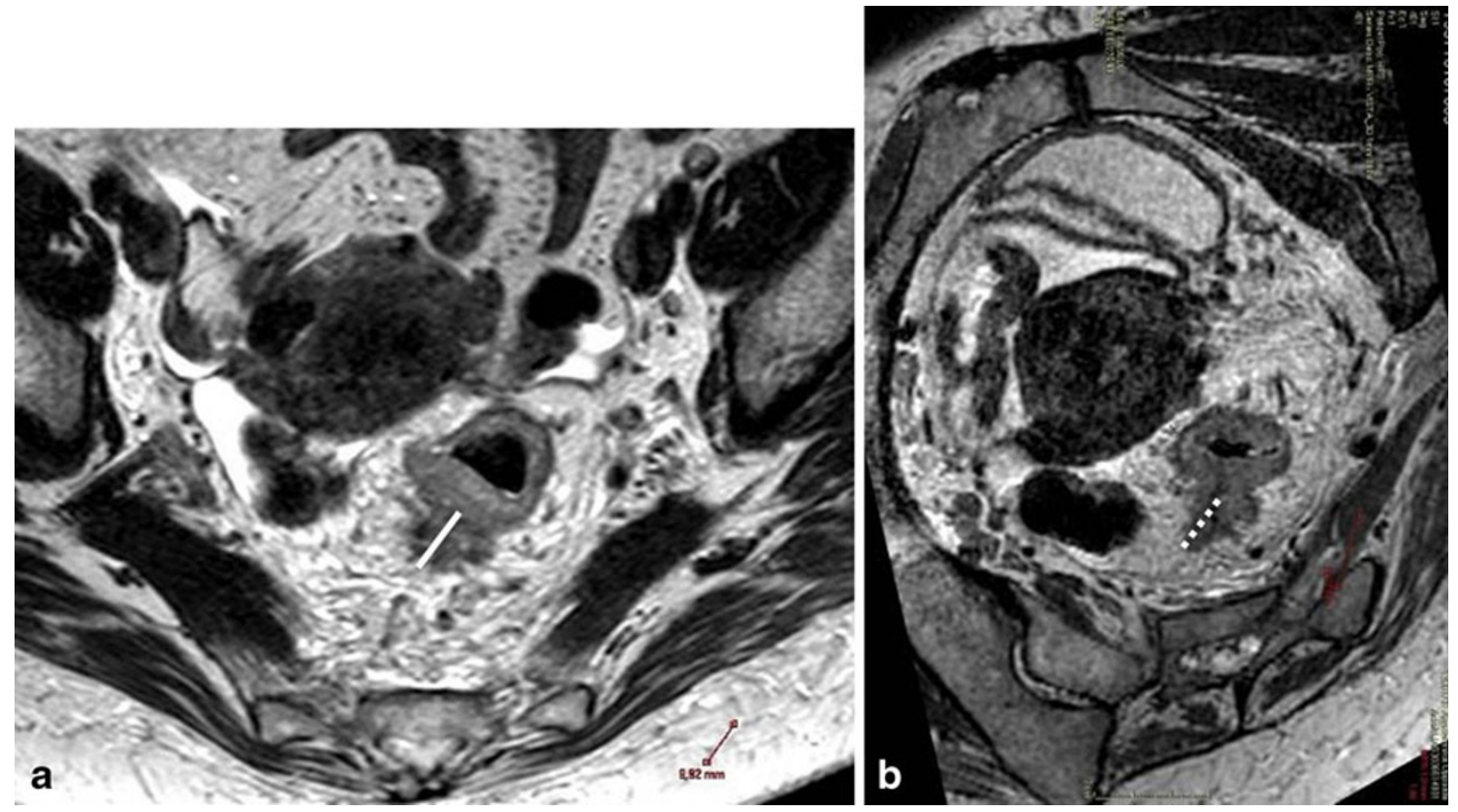

Fig. 13 Measurement of extramural tumour growth is dependent on the plane of imaging. True transverse TSE $(\mathbf{a}, 3 \mathrm{~T})$ image shows the extramural tumour growth to be $9 \mathrm{~mm}$ (white line). Reformatted image from original 3D T2-weighted images with plane reconstructed perpendicular to the rectal wall $(\mathbf{b}, 3 \mathrm{~T})$ shows that the extramural tumour component can be $20 \mathrm{~mm}$ (dotted line) 
or posterior and size of the mesorectum are also relevant to consider. We presently do not have precise knowledge of the relevance of each factor. Thus, the experience of the team is important. This experience can only develop if there is immediate follow-up after surgery with histopathology and later follow-up of clinical outcome.

\section{MRI protocols}

It is customary in most radiological review articles to begin with the MRI protocol. We chose, however, to begin with what the radiologist should report in order to make it easier to understand what the MRI protocol should consist of and the reason for this.

The indications for MRI of the pelvis in patients with rectal cancer are:

1. To evaluate the local extent of the tumour, before or perhaps also during/after preoperative treatment.

2. Local recurrence can also be an indication for MRI. This will be dealt with below.

3. Finally, sometimes MRI is used for a definitive diagnosis of rectal cancer (see above).

The basis for local assessment of rectal cancer is T2weighted imaging with turbo spin echo (TSE) [75]. This imaging should be performed in appropriate planes (Fig. 14). There is, however, no consensus about what are the essential planes, yet two requirements should be fulfilled: wherever distinction among T1, T2 and minimal T3 is important the imaging should preferably be perpendicular to the rectal wall, and whenever growth into neighbouring organs/tissues is not certain the imaging plane should be such as to show the smallest intervening fat (Table 1).

Sagittal plane imaging provides the best plane for assessment of growth into structures and organs anterior to the rectum where, especially in the female pelvis, the distance between the rectum and these structures is the least.

For low rectal tumours, imaging semi-coronally, perpendicular to the pelvic floor, which is often the same as parallel to the anal canal, provides very good depiction of the pelvic floor and the anal canal. Unfortunately, this is sometimes replaced with orthogonal coronal plane imaging, which is not the same.

Tumours from the ampulla of the rectum, especially polypoid tumours, growing dorsally and laterally, may be difficult to interpret. Because of the funnelled shape of the pelvic floor, adequate assessment is difficult on sagittal, orthogonal coronal or axial planes.

Three-dimensional imaging might overcome the problem of multiple imaging planes, saving time [76, 77].

At some institutions, the distinction between $\mathrm{T} 1, \mathrm{~T} 2$ and $\mathrm{T} 3$, especially in polypoid tumours, is solved by imaging in a plane perpendicular to the pelvic floor or administration of different types of rectal enema which expand the rectum $[78,79]$.

T1-weighted imaging seldom leads to increased information for experienced radiologists. Its use, however, does not increase imaging time considerably and may occasionally help with other diagnoses. Mucin-producing tumours might be better visualised with T1-weighted imaging compared with T2-weighted imaging with lower ET.

Contrast-enhanced imaging with gadolinium does not improve local staging [80]. Contrast-enhanced imaging only adds adverse effects and increases imaging time. Perfusion studies (see below) with both MRI and CT appear to provide information similar to ${ }^{18} \mathrm{~F}$-fluorodeoxyglucose (FDG)-positron emission tomography (PET) [81]; i.e. tumours with increased perfusion and metabolism are more likely to respond to preoperative (chemo-) radiotherapy (see below).

$D W I$ has attracted much attention recently. DWI could help to detect tumours similar to other abdominal malig-
Fig. 14 Value of imaging in other planes. The axial TSE image $(1.5 \mathrm{~T})$ (a) shows a tumour that might be interpreted as a small T3. The coronal TSE image, however, shows no extramural tumour growth. The tumour was a $\mathrm{T} 2$ at histopathology
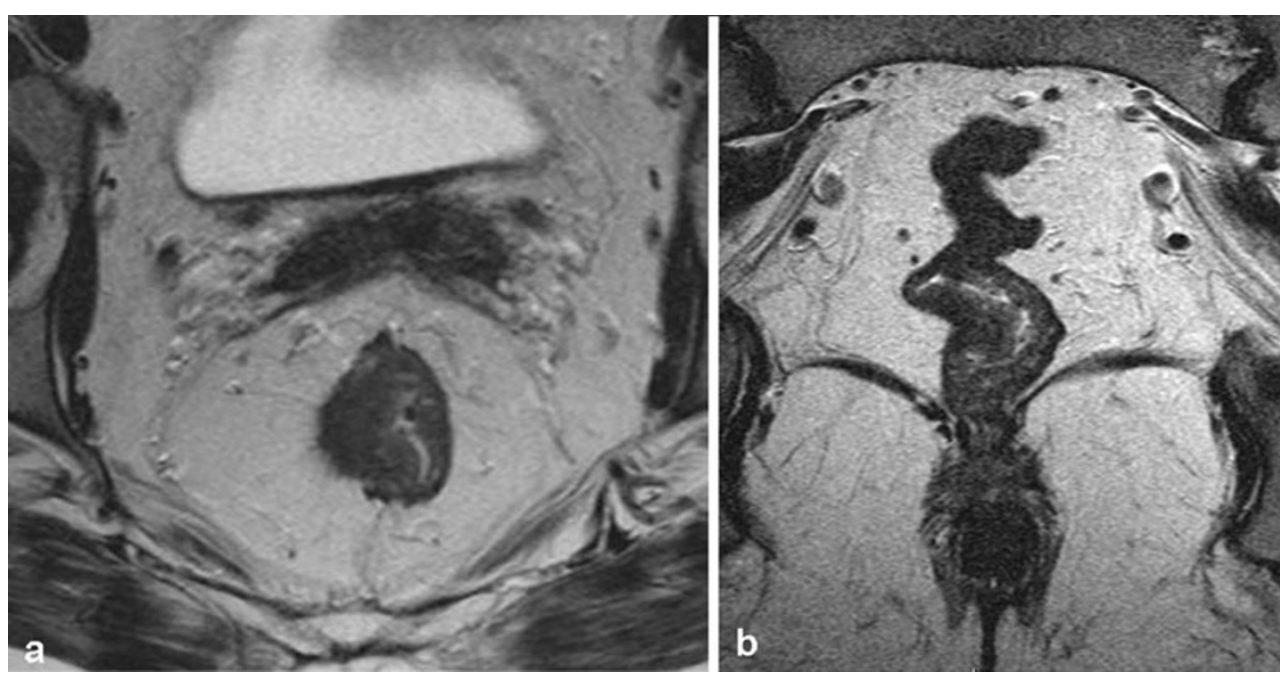
Table 1 Different imaging planes

\begin{tabular}{|c|c|c|c|}
\hline Plane & Advantage & Disadvantage & Usage \\
\hline Sagittal (orthogonal) & $\begin{array}{l}\text { Easy for measuring tumor height and length. } \\
\text { Best for assessment of involvement of } \\
\text { midline organs and structures }\end{array}$ & $\begin{array}{l}\text { Structures slightly lateral to midline not } \\
\text { easily assessed especially in female } \\
\text { patients }\end{array}$ & $\begin{array}{l}\text { Easily reproducible. } \\
\text { Recommended }\end{array}$ \\
\hline Axial (orthogonal) & $\begin{array}{l}\text { Easily recognizable by clinicians. Easy for } \\
\text { comparison with MRI or other imaging } \\
\text { modalities, especially comparison of lymph } \\
\text { nodes. Often best view of inguinal lymph } \\
\text { nodes }\end{array}$ & $\begin{array}{l}\text { Due to funnel-shaped form of pelvic } \\
\text { floor and anterior curve of } \\
\text { rectosigmoid, not enough for } \\
\text { adequate detailed analysis in many cases }\end{array}$ & $\begin{array}{l}\text { Easily reproducible. } \\
\text { Recommended }\end{array}$ \\
\hline Coronal orthogonal & None & Takes time of more important images & Not recommended \\
\hline $\begin{array}{l}\text { Semi-coronally } \\
\text { parallel to anal canal }\end{array}$ & $\begin{array}{l}\text { Visually informative for surgeons in low } \\
\text { rectal tumors }\end{array}$ & $\begin{array}{l}\text { Can be the same as perpendicular to } \\
\text { pelvic floor }\end{array}$ & Not essential \\
\hline $\begin{array}{l}\text { Perpendicular } \\
\text { to rectal wall }\end{array}$ & $\begin{array}{l}\text { Provides best differential of } \mathrm{T} 1, \mathrm{~T} 2 \text { and } \\
\text { minimal T3. Has to be repeated at all areas } \\
\text { where distinction between } \mathrm{T} 3 \text { and } \mathrm{T} 1-2 \text { is } \\
\text { important }\end{array}$ & $\begin{array}{l}\text { Needs either capable technicians or } \\
\text { presence of radiologists at the time } \\
\text { of imaging }\end{array}$ & Essential \\
\hline $\begin{array}{l}\text { Perpendicular } \\
\text { to anterior mesorectal fascia }\end{array}$ & $\begin{array}{l}\text { For anterior tumors or tumors with anterior } \\
\text { component, especially in female subjects }\end{array}$ & $\begin{array}{l}\text { Sometimes not necessary in cases of } \\
\text { obvious tumor growth into anterior } \\
\text { structures }\end{array}$ & $\begin{array}{l}\text { Important in } \\
\text { selected cases }\end{array}$ \\
\hline $\begin{array}{l}\text { Perpendicular } \\
\text { to pelvic floor }\end{array}$ & $\begin{array}{l}\text { For tumors growing dorsally and laterally } \\
\text { close to pelvic floor. Can provide coverage } \\
\text { of mesorectal lymph nodes }\end{array}$ & Not necessary in all cases & $\begin{array}{l}\text { Important in } \\
\text { selected cases }\end{array}$ \\
\hline $\begin{array}{l}\text { Perpendicular } \\
\text { to anal canal }\end{array}$ & $\begin{array}{l}\text { Most important plane for low tumors at the } \\
\text { level of pelvic floor or lower down }\end{array}$ & $\begin{array}{l}\text { Not essential for tumors completely } \\
\text { above the pelvic floor }\end{array}$ & $\begin{array}{l}\text { Not essential for } \\
\text { tumors completely } \\
\text { above the pelvic floor }\end{array}$ \\
\hline
\end{tabular}

nancies [82-84]. DWI cannot be used to confirm malignancy. DWI might also predict which patients have a higher likelihood of responding to treatment [85]. This, however, does not help treatment planning for the individual patient.

\section{Field strength}

More studies are coming regarding the accuracy of $3 \mathrm{~T}$, sometimes with and sometimes without comparison with $1.5 \mathrm{~T}$. The reported overall accuracy rate of T-staging with $3 \mathrm{~T}$ for rectal cancer has been $85-92 \%$. The overall sensitivity, specificity and accuracy for the detection of mesorectal nodal metastases reported are 64-80\%, 92-98\% and $88-95 \%$, respectively [86-90]. The reported sensitivity and specificity for $3 \mathrm{~T}$ are very similar to the corresponding figures mentioned above for $1.5 \mathrm{~T}$. The high signal of $3 \mathrm{~T}$ can, however, be used for thinner slice 3D T2-weighted imaging.

\section{Coils}

Body coil MRI has shown T- and N-stage accuracy ranging from $59 \%$ to $95 \%$ and $39 \%$ to $95 \%$, respectively. Endorectal coil MRI has shown improved T- and N-stage accuracy, with rates of $66 \%$ to $91 \%$ and $72 \%$ to $79 \%$, respectively $[91,92]$. While endorectal coils have comparable accuracies to endorectal ultrasound for distinction among T1-3 stages [93, 94], the diagnostic accuracy of these coils for demonstration of involvement of the mesorectal fascia would not be sufficient. Some authors have used a combination of both surface and endorectal coils, yet pelvic MRI after the placement of endorectal coil in addition to the phased-array coil has not been superior to the imaging with phased-array coil alone in the T-staging of rectal carcinomas [95]. Surface coils are easy to position and do not have the problems of endorectal coils. Furthermore, the most important piece of information, namely, involvement of the mesorectal fascia, is demonstrated easily with surface coils [96]. At present, phased-array MRI best fulfils the clinical requirements for preoperative staging of rectal cancer [97].

\section{Tumour status after preoperative treatment}

Several studies have evaluated MRI after and sometimes also during preoperative treatment. In the following, we use the term MRI2 for MRI performed after or during neoadjuvant treatment as opposed to MRI1, which is performed before therapy. The aims of studies concerning MRI2 could be summarised as the following:

1. Comparison between MRI2 and histopathology or between MRI2 and MRI1

2. Can MRI2 help change treatment? 
Aim 1 is chiefly academic, and does not influence treatment directly like aim 2 .

Aim 1, comparison between MRI2 and histopathology or between MRI2 and MRII: most tumours decrease in size being replaced by fibrosis with mucin pools [98-101], and studies on MRI2 have shown that the degree of tumour volume reduction correlates with tumour regression mainly based on a histopathological classification proposed by Dworak et al. [102]. Tumours that histopathologically respond have a good prognosis, particularly if a complete response (pCR) is seen [103]. It is, however, not entirely clear which staging (MRI1, MRI2 or postoperative histopathology) provides the best diagnostic and prognostic information. Though one study claims that MRI before treatment correlates better with prognosis and local recurrence than histopathology after preoperative treatment [104], the TNM staging after treatment still has prognostic value [105]. Unfortunately, as MRI2 is a relatively new concept its prognostic value has not been validated, especially because it is done only in a subset of patients and with different protocols.

Most radiological studies have concentrated on the correlation between MRI2 and histopathology and have shown moderate correlation varying between 67 and $84 \%$ [106-109], being worst for mucin-producing tumours (Fig. 15). The basis of most of these has been tumour volume measurements $[110,111]$.

Perfusion studies have been used for differentiation between viable and non-viable malignant cells based on microcirculation [112-114]. The basis of these observations is that viable tumours have increased and rapid blood flow, while fibrosis, necrosis and mucin pools, on the other hand, have slower perfusion. These studies have not found their way into clinical routine because of the complexity of the measurements [115], and not all investigators have reproduced the previous results $[116,117]$.

$D W I$ also changes with successful treatment as a result of decreasing cell density from abundant tumour cells to fibrosis and mucin pools, and changes in cell shape and size. It is not clear, however, which diffusion coefficient value is more important, the one measured at MRI1, at MRI2 or at the change from MRI1 to MRI2 [86]. More on DWI is provided below.

The abovementioned retrospective studies show that there are large and considerable overlaps between MRI2 values and different degrees of histopathological regression. Also, if MRI2 proved to provide more valuable information than histopathology, its use would be increased. To our knowledge, there is as of yet no prospective study comparing the prognostic value of MRI1 vs MRI2 vs histopathology, and this should probably be an aim of future studies.

Aim 2, treatment modification: if a tumour responds in such a way that surgical treatment can be altered or in practice is less extensive than primarily decided upon based on MRI1, then MRI2 is indicated (Figs. 16, 17). The surgical treatment for pretreated rectal cancer can be:

1. No surgery

2. Local excision

3. Standard TME

4. Extended TME

No surgery (wait and see or watchful waiting) can be offered to patients with no residual remaining tumour (or contraindication/refusal of surgery) [118]. Local excision can be offered to those patients with limited luminal disease $[119,120]$. Both these approaches, collectively termed "organ preservation", require adequate assessment of mesorectal lymph nodes as well (Table 2).
Fig. 15 Mucin-producing tumours are particularly difficult to evaluate after neo-adjuvant treatment. The difference between sagittal TSE images before (a) and after treatment (b) $(1.5 \mathrm{~T})$ can only be seen in findings such as mucosal oedema of the lower rectum (white arrow), and presacral oedema (black arrow). The tumour itself and it extension outside the rectum (hatched arrows) are virtually unchanged
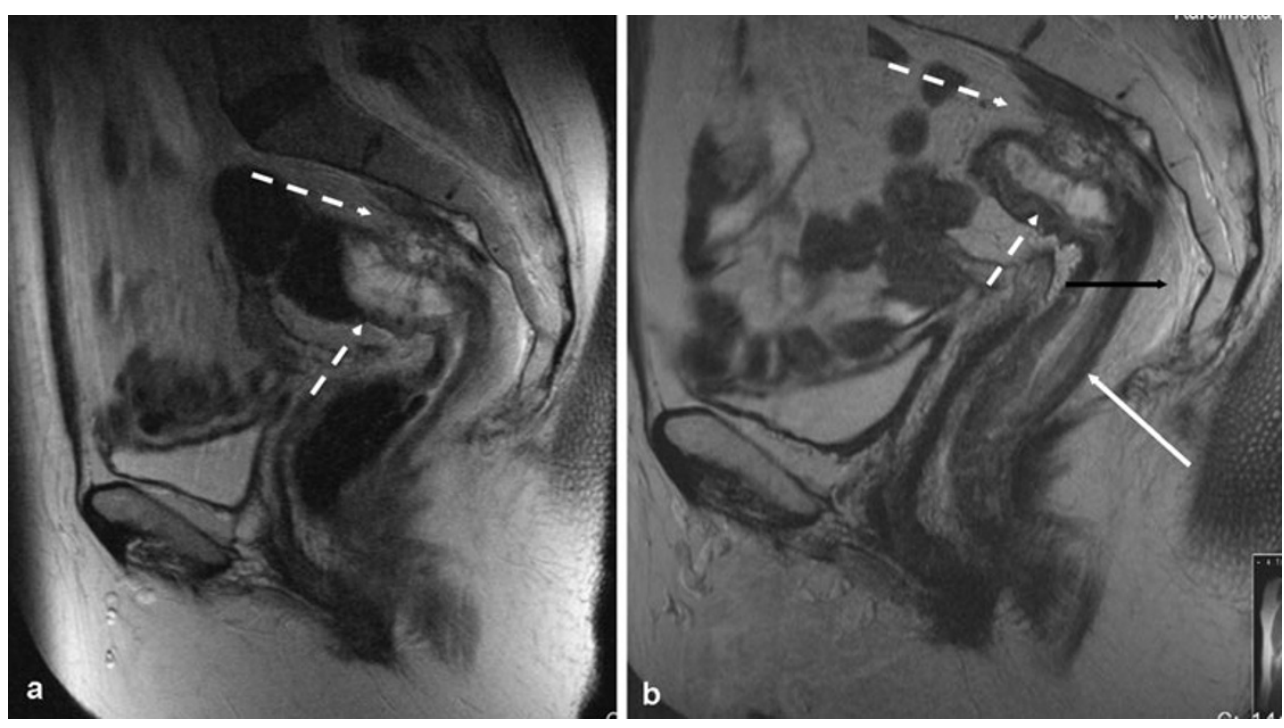
Fig. 16 Extensive large tumour (white arrow) on sagittal TSE (a) and axial TSE (b) images $(1.5 \mathrm{~T})$. The tumour extends to several important structures (dotted arrows). After neoadjuvant treatment, on TSE imaging $(\mathbf{c}, \mathbf{d})$ the tumor has shrunk considerably. The extension to nearby structures remains unaltered on the TSE image. Surgery therefore cannot be limited based on imaging after neo-adjuvant therapy
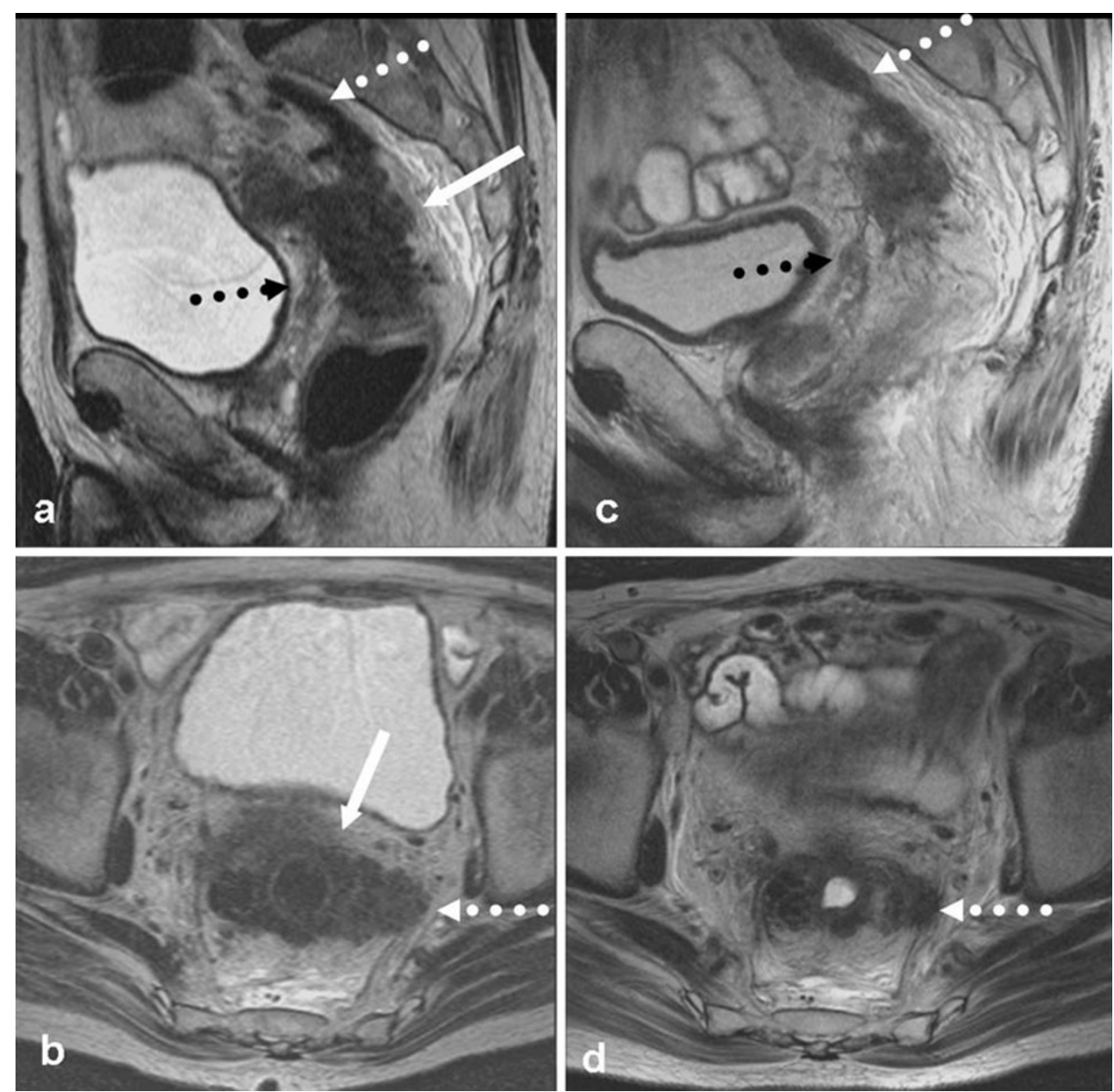

Table 2 describes in brief how surgical treatments of patients could change based on information obtained at MRI2. One should remember that early tumours do not require long-term neoadjuvant therapy and therefore no MRI2.

Fig. 17 Axial TSE images $(1.5 \mathrm{~T})$ of a large tumour (white solid arrow) before (a) and after (b) neo-adjuvant therapy. The tumour has shrunk tremendously, yet the extension to the uterus (dotted white arrow), the fasciae (black solid arrows) and the small intestine (dotted black arrows) are visible in the form of low-signal bands. The bands are composed of fibrosis, yet based on MRI, it is difficult to negate remaining tumour in the fibrotic strands
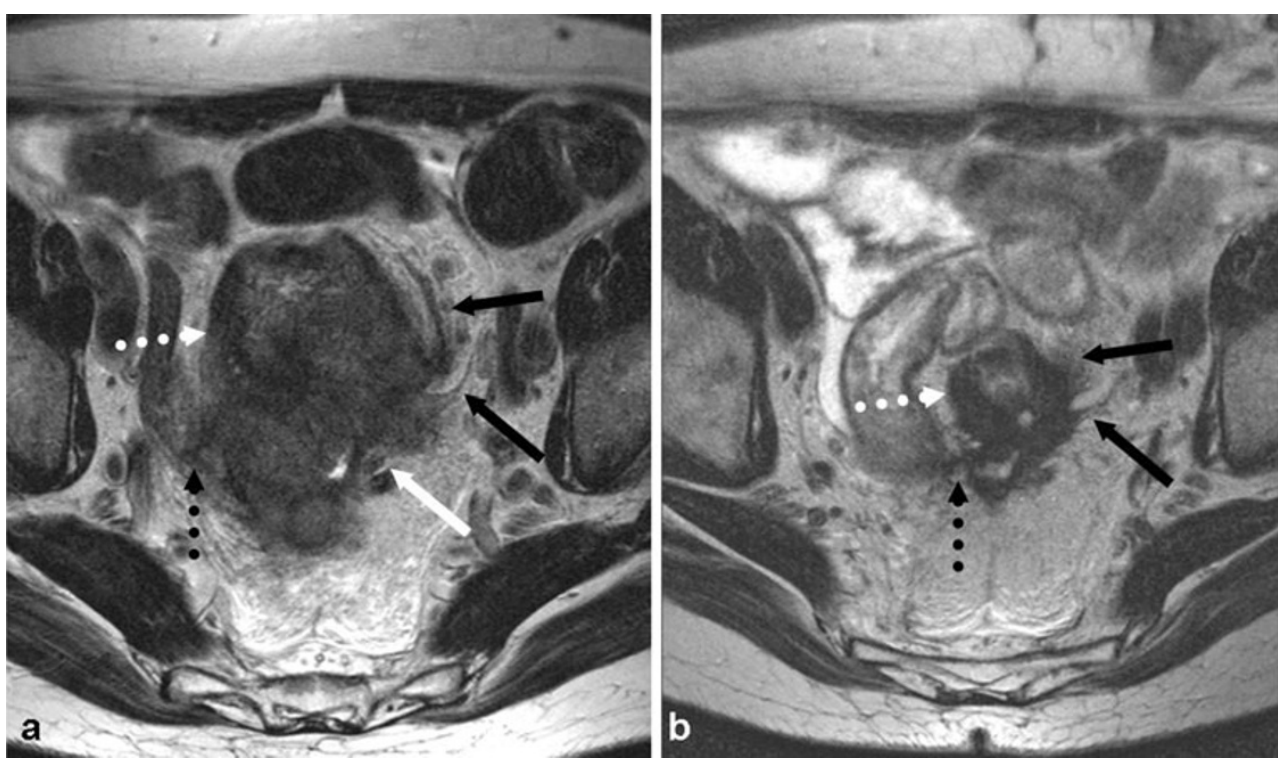
Table 2 Possible treatment modifications based on MRI after neoadjuvant therapy (MRI2) and its requirements. For discussion of different scenarios please refer to the text

\begin{tabular}{|c|c|c|c|c|}
\hline & & \multicolumn{3}{|c|}{ Planned surgery after neoadjuvant therapy } \\
\hline & & $\begin{array}{l}\text { No surgery or a } \\
\text { local excision }\end{array}$ & TME & Extended TME \\
\hline \multirow[t]{2}{*}{$\begin{array}{l}\text { Planned surgery before } \\
\text { neoadjuvant therapy based } \\
\text { on initial MRI (MRI1) }\end{array}$} & TME & $\begin{array}{l}\text { Scenario A; } \\
\text { requires: } \\
\text { 1. No remaining } \\
\text { malignant cells }\end{array}$ & $\begin{array}{l}\text { Scenario B; no added clinical value of } \\
\text { MRI2 }\end{array}$ & Scenario $\mathrm{C}$; only if tumor progresses \\
\hline & $\begin{array}{l}\text { Extended } \\
\text { TME }\end{array}$ & $\begin{array}{l}\text { 2. No metastatic } \\
\text { mesorectal } \\
\text { lymph nodes }\end{array}$ & $\begin{array}{l}\text { Scenario D; requires MRI2 to distinguish } \\
\text { reliably that fibrosis outside mesorectum } \\
\text { can be left alone }\end{array}$ & $\begin{array}{l}\text { Scenario E; relevant only if pattern of } \\
\text { extension to organs outside } \\
\text { mesorectal fascia changes }\end{array}$ \\
\hline
\end{tabular}

considered) and tumours larger than small ypT1-ypT2 (where TME should be considered) [121, 122].

2. In addition, MRI2 should detect disappearance of all extramural malignant metastases and lymph nodes.

In one study of restaging irradiated tumours, MRI2 had an accuracy of $52 \%$ in T-staging and $68 \%$ in N-staging. Poor agreement between post-combined chemoradiotherapy MRI2 and pathological staging was observed in both T- $(k=0.017)$ and $\mathrm{N}$-staging $(k=0.031)$. Most of the inaccuracy in $\mathrm{T}$ - and $\mathrm{N}$-staging is caused by over-staging [123]. The problem with MRI is believed to be that it cannot completely differentiate fibrosis from viable residual tumours. Though fibrosis shows lower signal than tumour on T2-weighted imaging, there is still considerable overlap between normal viable tumour tissue and fibrosis (Fig. 18) [124]. In a recent retrospective study [111], the authors used a combination of tumour volume reduction rate and original tumour volume to predict ypT0-2 in 67 patients. They found that with an initial tumour volume of $\leq 50 \mathrm{~cm}^{3}$ at MRI1 and a reduction rate $\geq 75 \%$, the excised tumour was always ypT0-2. Figures 17 and 18 both demonstrate these cases. Tiny strands and smooth slight thickening of fascia with very low signal on T2-weighted imaging are most commonly associated with absence of tumour at histopathology.

This is an interesting development; however, it cannot help distinguish scenario A from other scenarios. However, at the European Society of Gastrointestinal and Abdominal Radiology (ESGAR) meeting in 2009 and the ECR meeting 2010 some preliminary promising results from one multicentre study were unveiled (congress proceedings and Dr. Beets-Tan, personal communication). The approach was offering surveillance with endoscopy and follow-up MRI instead of surgery (wait-and-watch approach) if no tumour residue could be detected. DWI should be used in addition and the absence of any tumour signal has shown to improve
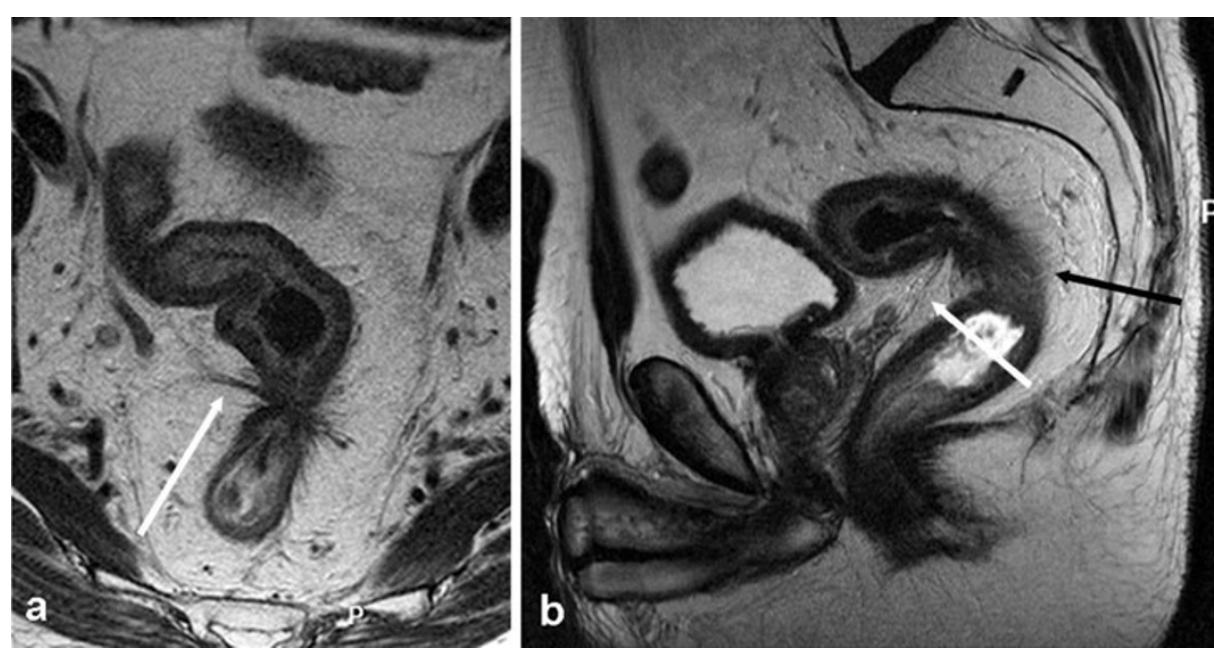

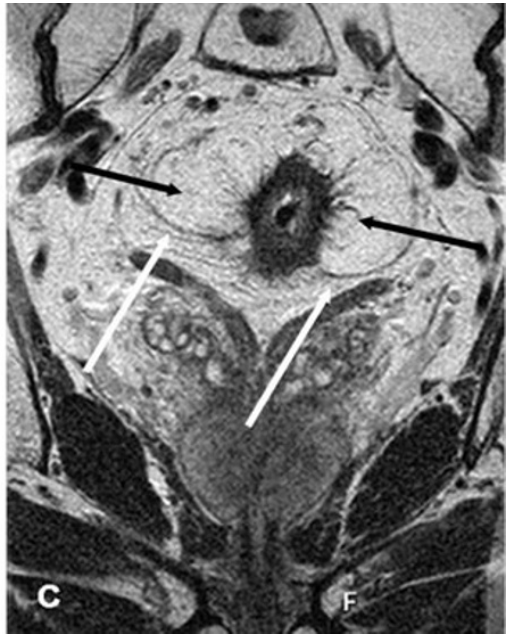

infiltration (black arrows) in the perirectal fat. No tumour signal has returned. The tumour was a T1 at histopathology
Fig. 18 Axial (a), sagittal (b) and axial (c) TSE images (1.5 T) of a rectosigmoid cancer after neoadjuvant therapy. There is remaining thickening of the peritoneal reflection (white arrows) and low signal 
Fig. 19 Axial (a) and parasagittal (b) TSE images $(1.5 \mathrm{~T})$ of a tumour recurrence (arrows). The tumour is an expansive mass located asymmetrically in front of the sacrum, lying against the piriformis muscle (black arrow) and the pelvic floor dorsally (dotted arrow)
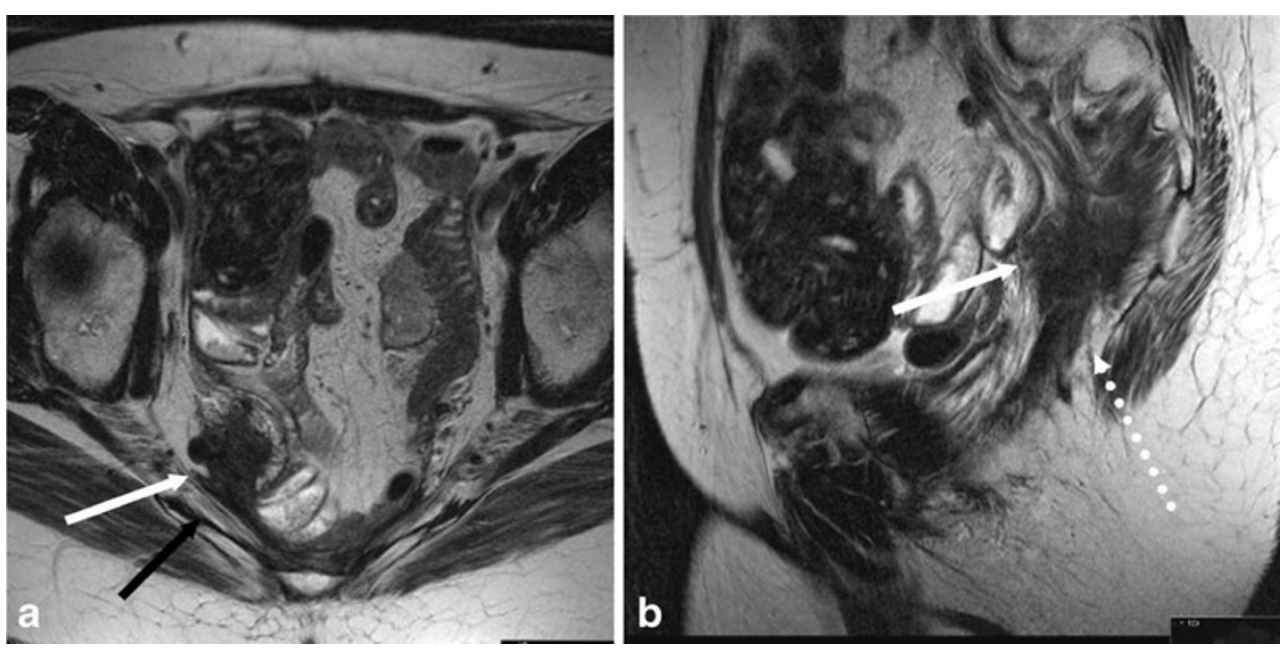

the accuracy of diagnosis of complete response to approximately $80 \%$ (ECR 2010).

Aside from T-staging, the status of the lymph nodes remains unclear [125], and some studies have found poor results when lymph nodes are staged after neoadjuvant therapy and compared with histopathology [126]. This group found a significant difference in node positivity between MRI and pathological staging $(P=0.005)$. Another study looked at matched lymph nodes after treatment and found that the most reliable predictors for identifying
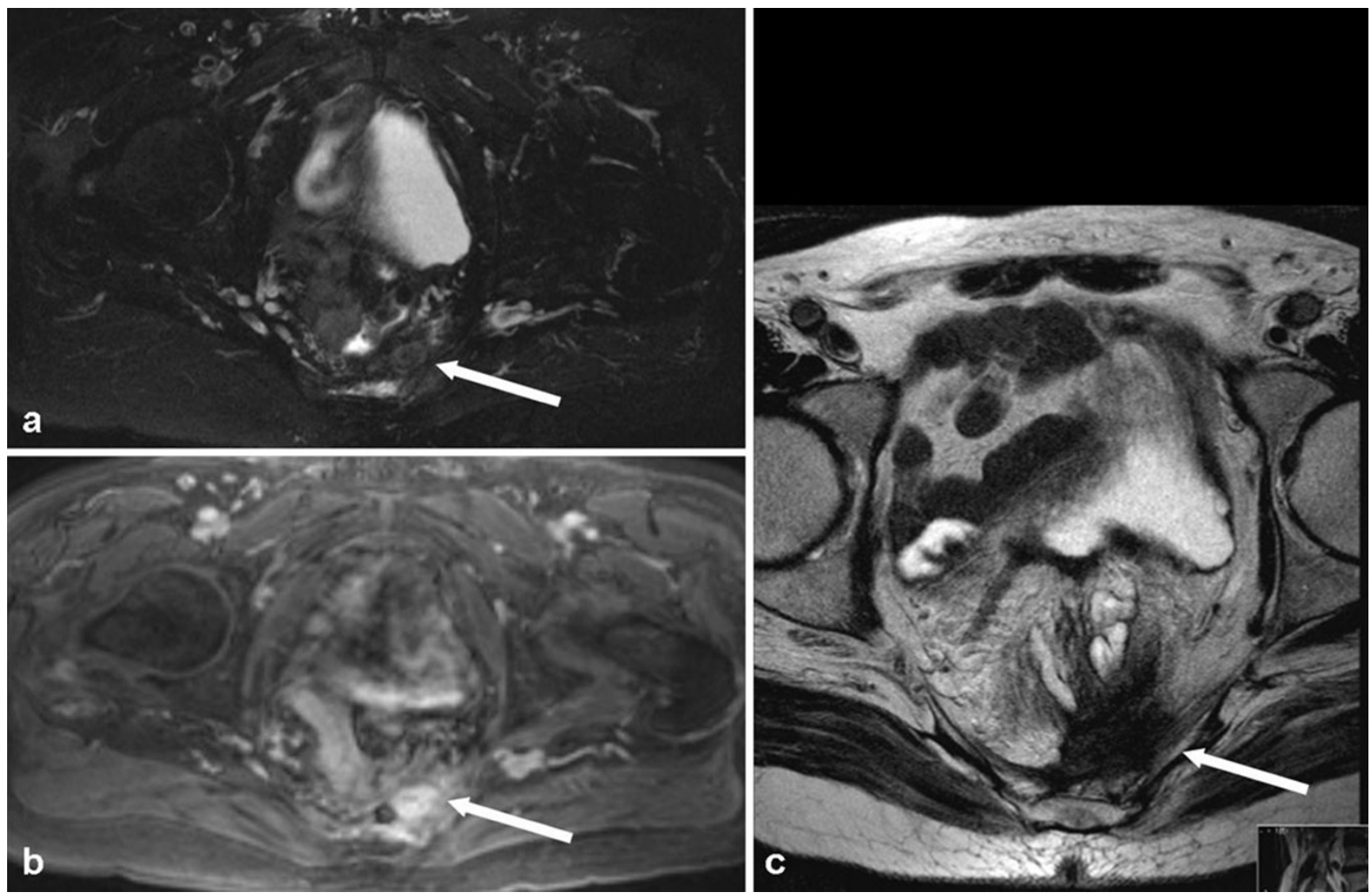

clearly in b. Axial high-resolution TSE, however, depicts the tumour

Fig. 20 Axial images $(1.5 \mathrm{~T})$ with $\mathrm{T} 2$-weighted image with fat saturation (a), and T1-weighted image after contrast enhancement with fat saturation (b). The tumour is barely visible in a, and more best, also showing its growth pattern and relation to neighbouring structures 
benign nodes were obtained after using USPIO [127]. There are two major problems with application of the results of this study into everyday practice:

1. Unavailability of USPIO as detailed before

2. The study concerns matched lymph nodes and not all lymph nodes

Our own experience, and that of others, however, is that small lymph nodes on MRI1 disappear completely on MRI2, and the absence of any visible lymph nodes on T2weighted imaging and DWI at MRI2 is almost always reported as N0 at histopathology. In summary, $4-25 \%$ of patients can respond with a pathologically complete response locally, and this may change the role of MRI before surgery, or perhaps follow-up MRI [128].

There are only anecdotes of tumour progression under treatment reported and seen only when a tumour ruptures or treatment is withheld because of some complications (e.g. myocardial infarction). In an unpublished study of 99 MRI2 and their comparison with MRI1, there were no cases of progression (Torkzad et al., personal communication).

In a patient with tumour extending outside the mesorectal fascia at MRI1 and no signs of growth towards the mesorectal fascia at MRI2, less extensive surgery could possibly be an option [99]. This study did not show any additional value for MRI2 compared with MRI1. The main reason is that MRI cannot rule out remaining tumour cells in remaining fibrosis [110]. Our experience, and that of others, however, is that if all tumour tissues reaching the mesorectal fascia and beyond are replaced by only very thin spiculations with very low signal intensity on T2-weighted imaging, the likelihood of tumour being found at histopathology is not high. Some surgeons use this for limiting their surgery to standard TME and not removing other organs. Other surgeons may, however, be reluctant to leave fibrosis extending to neighbouring organs at surgery.

Different forms of therapy might induce different imaging findings at different time periods, an issue that has not been addressed adequately in the literature. Ongoing response to chemo-radiotherapy has been reported for up to 12 weeks post-treatment, which has important clinical implications regarding the most appropriate time to operate or perform MRI2 [129].

In summary, the importance of MRI2 has been limited thus far for clinical use in the individual patient. This could change in the future, however, pending newer studies and newer methods. Certainly not all patients need MRI2. We have to define and study the following:

1. When is the optimal timing of MRI2?

2. What is the optimal imaging method for MRI2?

3. Which patients need MRI2?
4. What gives the best prognostic information, MRI1, MRI2 or histopathology?

5. How can treatment plans be changed based on MRI2?

\section{Local recurrence}

The imaging indications in local recurrence are to verify or identify local recurrence, and to assess the extent of the local recurrence. Owing to improved treatment strategies, the prognosis in rectal cancer has improved dramatically, with rectal cancer now having a better prognosis than colon cancer [130]. MRI is used widely for diagnosis and surgical planning when recurrence is suspected [131, 132].

The local recurrence rate has decreased greatly. In the postTME era, most recurrences occur at the anastomotic site, presacrally or at the level of the pelvic floor, with very few at the lateral pelvic side walls in the European material (Fig. 19) $[133,134]$. The best sequence for imaging is TSE, although contrast enhancement can be useful at times (Fig. 20).

Pelvic surveillance by MRI does not seem justified as part of routine follow-up after a curative resection for rectal cancer and should be reserved for selective imaging of patients with clinical, colonoscopic and/or biochemically suspected recurrent disease [135-141].

\section{Conclusion}

Magnetic resonance imaging is a valuable tool for the planning of treatment in rectal cancer. It is the single most important technique in the local staging of patients with rectal cancer. MRI provides reliable risk allocation for different patient groups, helping to choose different treatment regimens in the context of multidisciplinary meetings with a common terminology [132]. The MR techniques are continuously improving, and as there are several limitations in rectal cancer staging, especially for lymph node staging, we can foresee improvements. The role of MRI after preoperative treatment has to be defined and evaluated. Finally, MRI has proven its role in patients with local recurrence.

\section{References}

1. Martling A, Holm T, Bremmer S, Lindholm J, Cedermark B, Blomqvist L (2003) Prognostic value of preoperative magnetic resonance imaging of the pelvis in rectal cancer. Br J Surg 90 (11):1422-1428

2. Brown G, Davies S, Williams GT, Bourne MW, Newcombe RG, Radcliffe AG, Blethyn J, Dallimore NS, Rees BI, Phillips CJ, 
Maughan TS (2004) Effectiveness of preoperative staging in rectal cancer: digital rectal examination, endoluminal ultrasound or magnetic resonance imaging? Br J Cancer 91(1):23-29

3. LeBlanc JK (2007) Imaging and management of rectal cancer. Nat Clin Pract Gastroenterol Hepatol 4(12):665-676

4. Smith N, Brown G (2008) Preoperative staging in rectal cancer. Acta Oncol 47:20-31

5. Taylor A, Sheridan M, McGee S, Halligan S (2005) Preoperative staging of rectal cancer by MRI; results of a UK survey. Clin Radiol 60(5):579-586

6. Matsuoka H, Nakamura A, Masaki T, Sugiyama M, Takahara T, Hachiya J, Atomi Y (2003) A prospective comparison between multidetector-row computed tomography and magnetic resonance imaging in the preoperative evaluation of rectal carcinoma. Am J Surg 185(6):556-559

7. Burton S, Brown G, Daniels IR, Norman AR, Mason B, Cunningham D (2006) MRI directed multidisciplinary team preoperative treatment strategy: the way to eliminate positive circumferential margins? Br J Cancer 94(3):351-357

8. Strassburg J, Lewin A, Ludwig K, Kilian L, Linke J, Loy V, Knuth P, Püttcher O, Ruehl U, Stöckmann F, Hackenthal M, Hopfenmüller W, Huppertz A (2007) Optimised surgery (socalled TME surgery) and high-resolution MRI in the planning of treatment of rectal carcinoma. Langenbecks Arch Surg 392 (2): $179-188$

9. Burton S, Brown G, Daniels I, Norman A, Swift I, Abulafi M, Wotherspoon A, Tait D (2006) MRI identified prognostic features of tumors in distal sigmoid, rectosigmoid, and upper rectum: treatment with radiotherapy and chemotherapy. Int $\mathrm{J}$ Radiat Oncol Biol Phys 65(2):445-451

10. Nicholls RJ, Tekkis PP (2008) Multidisciplinary treatment of cancer of the rectum: a European approach. Surg Oncol Clin N Am 17(3):533-551, viii

11. Branagan G, Chave H, Fuller C, McGee S, Finnis D (2004) Can magnetic resonance imaging predict circumferential margins and TNM stage in rectal cancer? Dis Colon Rectum 47(8):13171322

12. Bipat S, Glas AS, Slors FJ, Zwinderman AH, Bossuyt PM, Stoker J (2004) Rectal cancer: local staging and assessment of lymph node involvement with endoluminal US, CT, and MR imaging-a meta-analysis. Radiology 232(3):773-783

13. Rovera F, Dionigi G, Boni L, Cutaia S, Diurni M, Dionigi R (2007) The role of EUS and MRI in rectal cancer staging. Surg Oncol 16(Suppl 1):S51-S52

14. MERCURY Study Group (2006) Diagnostic accuracy of preoperative magnetic resonance imaging in predicting curative resection of rectal cancer: prospective observational study. BMJ 333(7572):779-785

15. Suzuki C, Torkzad MR, Tanaka S, Palmer G, Lindholm J, Holm T, Blomqvist L (2008) The importance of rectal cancer MRI protocols on interpretation accuracy. World J Surg Oncol 6:89

16. Brown G (2005) Thin section MRI in multidisciplinary preoperative decision making for patients with rectal cancer. $\mathrm{Br} \mathrm{J}$ Radiol 78(Spec No 2):S117-S127

17. Kim YW, Kim NK, Min BS, Kim H, Pyo J, Kim MJ, Cha SH (2008) A prospective comparison study for predicting circumferential resection margin between preoperative MRI and whole mount sections in mid-rectal cancer: significance of different scan planes. Eur J Surg Oncol 34(6):648-654

18. Bond S, Joshi N, Petroudi S, Brady M (2007) Estimating the mesorectal fascia in MRI. Inf Process Med Imag 20:650-661

19. Purkayastha S, Tekkis PP, Athanasiou T, Tilney HS, Darzi AW, Heriot AG (2007) Diagnostic precision of magnetic resonance imaging for preoperative prediction of the circumferential margin involvement in patients with rectal cancer. Colorectal Dis 9 (5):402-411
20. Rafaelsen SR, Sørensen T, Jakobsen A, Bisgaard C, Lindebjerg J (2008) Transrectal ultrasonography and magnetic resonance imaging in the staging of rectal cancer. Effect of experience. Scand J Gastroenterol 43(4):440-446

21. Goh V, Halligan S, Bartram CI (2004) Local radiological staging of rectal cancer. Clin Radiol 59(3):215-226

22. Salerno G, Daniels IR, Brown G (2006) Magnetic resonance imaging of the low rectum: defining the radiological anatomy. Colorectal Dis 8(Suppl 3):10-13

23. Salerno G, Sinnatamby C, Branagan G, Daniels IR, Heald RJ, Moran BJ (2006) Defining the rectum: surgically, radiologically and anatomically. Colorectal Dis 8(Suppl 3):5-9

24. Torkzad MR, Blomqvist L (2005) The mesorectum: morphometric assessment with magnetic resonance imaging. Eur Radiol 15(6): 1184-1191

25. Allen SD, Gada V, Blunt DM (2007) Variation of mesorectal volume with abdominal fat volume in patients with rectal carcinoma: assessment with MRI. Br J Radiol 80(952):242-247

26. Torkzad MR, Hansson KA, Lindholm J, Martling A, Blomqvist L (2007) Significance of mesorectal volume in staging of rectal cancer with magnetic resonance imaging and the assessment of involvement of the mesorectal fascia. Eur Radiol 17(7):1694 1699

27. Peschaud F, Cuenod CA, Benoist S, Julié C, Beauchet A, Siauve N, Taieb-Kasbi F, Penna C, Nordlinger B (2005) Accuracy of magnetic resonance imaging in rectal cancer depends on location of the tumor. Dis Colon Rectum 48(8):1603-1609

28. Diop M, Parratte B, Tatu L, Vuillier F, Brunelle S, Monnier G (2003) "Mesorectum": the surgical value of an anatomical approach. Surg Radiol Anat 25(3-4):290-304

29. Lindsey I, Warren B, Mortensen N (2004) Optimal total mesorectal excision for rectal cancer is by dissection in front of Denonvilliers' fascia (comment on Br J Surg 2004; 91: 121123). Br J Surg 91 (7): 897

30. Lahaye MJ, Engelen SM, Nelemans PJ, Beets GL, van de Velde CJ, van Engelshoven JM, Beets-Tan RG (2005) Imaging for predicting the risk factors — the circumferential resection margin and nodal disease - of local recurrence in rectal cancer: a meta-analysis. Semin Ultrasound CT MR 26(4):259-268

31. Baik SH, Kim NK, Lee KY, Sohn SK, Cho CH, Kim MJ, Kim H, Shinn RK (2008) Factors influencing pathologic results after total mesorectal excision for rectal cancer: analysis of consecutive 100 cases. Ann Surg Oncol 15(3):721-728

32. Wolberink SV, Beets-Tan RG, Nagtegaal ID, Wiggers T (2006) Preoperative assessment of the circumferential margin in rectal cancer is more informative in treatment planning than the $T$ stage. Tech Coloproctol 10(3):171-176

33. Mathur P, Smith JJ, Ramsey C, Owen M, Thorpe A, Karim S, Burke C, Ramesh S, Dawson PM (2003) Comparison of CT and MRI in the pre-operative staging of rectal adenocarcinoma and prediction of circumferential resection margin involvement by MRI. Colorectal Dis 5(5):396-401

34. Poon FW, McDonald A, Anderson JH, Duthie F, Rodger C, McCurrach G, McKee RF, Horgan PG, Foulis AK, Chong D, Finlay IG (2005) Accuracy of thin section magnetic resonance using phased-array pelvic coil in predicting the T-staging of rectal cancer. Eur J Radiol 53(2):256-262

35. Kraaz W (2007) Magnetic resonance imaging for preoperative staging of rectal cancer in clinical practice: high accuracy in predicting circumferential margin with clinical benefit. Colorectal Dis 9(5):412-419

36. Ferri M, Laghi A, Mingazzini P, Iafrate F, Meli L, Ricci F, Passariello R, Ziparo V (2005) Pre-operative assessment of extramural invasion and sphincteral involvement in rectal cancer by magnetic resonance imaging with phased-array coil. Colorectal Dis 7(4):387-393 
37. Strassburg J, Junginger T, Trinh T, Püttcher O, Oberholzer K, Heald RJ, Hermanek P (2008) Magnetic resonance imaging (MRI)-based indication for neoadjuvant treatment of rectal carcinoma and the surrogate endpoint CRM status. Int $\mathrm{J}$ Colorectal Dis 23(11):1099-1107

38. Glimelius B (2001) Pre- or postoperative radiotherapy in rectal cancer-more to learn? Radiother Oncol 61(1):1-5

39. Valentini V, Aristei C, Glimelius B, Minsky BD, Beets-Tan R, Borras JM, Haustermans K, Maingon P, Overgaard J, Pahlman L, Quirke P, Schmoll HJ, Sebag-Montefiore D, Taylor I, Van Cutsem E, Van de Velde C, Cellini N, Latini P, Committee S (2009) Multidisciplinary rectal cancer management: 2nd European Rectal Cancer Consensus Conference (EURECA-CC2). Radiother Oncol 92(2):148-163

40. Taylor A, Slater A, Mapstone N, Taylor S, Halligan S (2007) Staging rectal cancer: MRI compared to MDCT. Abdom Imaging 32(3):323-327

41. Kim NK, Min BS, Kim H, Pyo J, Kim MJ, Cha SH (2008) A prospective comparison study for predicting circumferential resection margin between preoperative MRI and whole mount sections in mid-rectal cancer: significance of different scan planes. Eur J Surg Oncol 34(6):648-654

42. Taylor FG, Swift RI, Blomqvist L, Brown G (2008) A systematic approach to the interpretation of preoperative staging MRI for rectal cancer. AJR Am J Roentgenol 191(6):1827-1835

43. Rao SX, Zeng MS, Xu JM, Qin XY, Chen CZ, Li RC, Hou YY (2007) Assessment of $T$ staging and mesorectal fascia status using high-resolution MRI in rectal cancer with rectal distention. World J Gastroenterol 13(30):4141-4146

44. Slater A, Halligan S, Taylor SA, Marshall M (2006) Distance between the rectal wall and mesorectal fascia measured by MRI: effect of rectal distension and implications for preoperative prediction of a tumour-free circumferential resection margin. Clin Radiol 61(1):65-70

45. Engelen SM, Beets GL, Beets-Tan RG (2007) Role of preoperative local and distant staging in rectal cancer. Onkologie 30(3):141-145

46. Matsuoka H, Nakamura A, Sugiyama M, Hachiya J, Atomi Y, Masaki T (2004) MRI diagnosis of mesorectal lymph node metastasis in patients with rectal carcinoma. What is the optimal criterion? Anticancer Res 24(6):4097-4101

47. Bianchi P, Ceriani C, Palmisano A, Pompili G, Passoni GR, Rottoli M, Cappellani A, Montorsi M (2006) A prospective comparison of endorectal ultrasound and pelvic magnetic resonance in the preoperative staging of rectal cancer. Ann Ital Chir 77(1):41-46

48. Panzironi G, De Vargas MM, Manganaro L, Ballesio L, Ricci F, Casale A, Campagnano D (2004) Preoperative locoregional staging of rectal carcinoma: comparison of MR. TRUS and Multislice CT. Personal experience. Radiol Med 107(4):344355

49. Kim JH, Beets GL, Kim MJ, Kessels AG, Beets-Tan RG (2004) High-resolution MR imaging for nodal staging in rectal cancer: are there any criteria in addition to the size? Eur J Radiol 52 (1):78-83

50. Koh DM, Brown G, Husband JE (2006) Nodal staging in rectal cancer. Abdom Imaging 31(6):652-659

51. Matsuoka H, Nakamura A, Masaki T, Sugiyama M, Nitatori T, Ohkura Y, Sakamoto A, Atomi Y (2007) Optimal diagnostic criteria for lateral pelvic lymph node metastasis in rectal carcinoma. Anticancer Res 27(5B):3529-3533

52. Matsuoka H, Masaki T, Sugiyama M, Nakamura A, Takahara T, Hachiya J, Atomi Y (2004) Gadolinium enhanced endorectal coil and air enema magnetic resonance imaging as a useful tool in the preoperative examination of patients with rectal carcinoma. Hepatogastroenterology 51(55):131-135
53. Koh DM, Brown G, Temple L, Raja A, Toomey P, Bett N, Norman AR, Husband JE (2004) Rectal cancer: mesorectal lymph nodes at MR imaging with USPIO versus histopathologic findings - initial observations. Radiology 231(1):91-99

54. Lahaye MJ, Engelen SM, Kessels AG, de Bruïne AP, von Meyenfeldt MF, van Engelshoven JM, van de Velde CJ, Beets GL, Beets-Tan RG (2008) USPIO-enhanced MR imaging for nodal staging in patients with primary rectal cancer: predictive criteria. Radiology 246(3):804-811

55. Lin G, Ho KC, Wang JJ, Ng KK, Wai YY, Chen YT, Chang CJ, $\mathrm{Ng} \mathrm{SH}$, Lai CH, Yen TC (2008) Detection of lymph node metastasis in cervical and uterine cancers by diffusion-weighted magnetic resonance imaging at $3 \mathrm{~T}$. J Magn Reson Imaging 28:128-135

56. Beets-Tan RGH, Lambregts DMJ, Beets GL, Engelen SME, Voth V, Leiner T, Lahaye MJ (2009) Gadovosfeset trisodium (Vasovist ${ }^{\circledR}$ ) enhanced MR lymph node detection: initial observations. Open Magn Reson J 2:28-32

57. Lahaye MJ, Kessels AG, Beets GL (2008) Location of involved mesorectal and extramesorectal lymph nodes in patients with primary rectal cancer: preoperative assessment with MR imaging. Eur J Surg Oncol 34(7):776-781

58. Aigner F, Trieb T, Ofner D, Margreiter R, Devries A, Zbar AP, Fritsch H (2007) Anatomical considerations in TNM staging and therapeutical procedures for low rectal cancer. Int J Colorectal Dis 22(11):1339-1346

59. Koh DM, Brown G, Temple L, Blake H, Raja A, Toomey P, Bett N, Farhat S, Norman AR, Daniels I, Husband JE (2005) Distribution of mesorectal lymph nodes in rectal cancer: in vivo MR imaging compared with histopathological examination. Initial observations. Eur Radiol 15(8):1650-1657

60. Arii K, Takifuji K, Yokoyama S, Matsuda K, Higashiguchi T, Tominaga T, Oku Y, Tani M, Yamaue H (2006) Preoperative evaluation of pelvic lateral lymph node of patients with lower rectal cancer: comparison study of MR imaging and CT in 53 patients. Langenbecks Arch Surg 391(5):449-454

61. Yano H, Moran BJ (2008) The incidence of lateral pelvic sidewall nodal involvement in low rectal cancer may be similar in Japan and the West. Br J Surg 95(1):33-49

62. Quirke P, Cuvelier C, Ensari A, Glimelius B, Laurberg S, Ortiz H, Piard F, Punt CJ, Glenthoj A, Pennickx F, Seymour M, Valentini V, Williams G, Nagtegaal ID (2010) Evidence-based medicine: the time has come to set standards for staging. J Pathol 221(4):357-360

63. Salerno G, Daniels I, Heald RJ, Brown G, Moran BJ (2004) Management and imaging of low rectal carcinoma. Surg Oncol 13(2-3):55-61

64. Shihab OC, Moran BJ, Heald RJ, Quirke P, Brown G (2009) MRI staging of low rectal cancer. Eur Radiol 19(3):643-650

65. Salerno GV, Daniels IR, Moran BJ, Heald RJ, Thomas K, Brown G (2009) Magnetic resonance imaging prediction of an involved surgical resection margin in low rectal cancer. Dis Colon Rectum 52(4):632-639

66. Torkzad M, Lindholm J, Martling A, Blomqvist L (2003) Retrospective measurement of different size parameters of nonradiated rectal cancer on MR images and pathology slides and their comparison. Eur Radiol 13(10):2271-2277

67. Smith NJ, Barbachano Y, Norman AR, Swift RI, Abulafi AM, Brown G (2008) Prognostic significance of magnetic resonance imaging-detected extramural vascular invasion in rectal cancer. Br J Surg 95(2):229-236

68. Smith NJ, Shihab O, Arnaout A, Swift RI, Brown G (2008) MRI for detection of extramural vascular invasion in rectal cancer. AJR Am J Roentgenol 191(5):1517-1522

69. Strassburg J (2004) Magnetic resonance imaging in rectal cancer: the MERCURY experience. Tech Coloproctol 8(Suppl 1):s16-s18 
70. Brown G, Daniels IR (2005) Preoperative staging of rectal cancer: the MERCURY research project. Recent Results Cancer Res 165:58-74

71. MERCURY Study Group (2007) Extramural depth of tumor invasion at thin-section MR in patients with rectal cancer: results of the MERCURY study. Radiology 243(1):132-139

72. Park SH (2008) Degree of error of thin-section MR in measuring extramural depth of tumor invasion in patients with rectal cancer. Radiology 246(2):647

73. Low RN, McCue M, Barone R, Saleh F, Song T (2003) MR staging of primary colorectal carcinoma: comparison with surgical and histopathologic findings. Abdom Imaging 28 (6):784-793

74. Guillem JG, Díaz-González JA, Minsky BD, Valentini V, Jeong SY, Rodriguez-Bigas MA, Coco C, Leon R, Hernandez-Lizoain JL, Aristu JJ, Riedel ER, Nitti D, Wong WD, Pucciarelli S (2008) cT3N0 rectal cancer: potential overtreatment with preoperative chemoradiotherapy is warranted. J Clin Oncol 26 (3):368-373

75. O'Neil BH, Tepper JE (2007) Current options for the management of rectal cancer. Curr Treat Options Oncol 8 (5):331-338

76. Zhang XM, Zhang HL, Yu D, Dai Y, Bi D, Prince MR, Li C (2008) 3-T MRI of rectal carcinoma: preoperative diagnosis, staging, and planning of sphincter-sparing surgery. AJR Am J Roentgenol 190(5):1271-1278

77. Kim H, Lim JS, Choi JY, Park J, Chung YE, Kim MJ, Choi E, Kim NK, Kim KW (2010) Rectal cancer: comparison of accuracy of local-regional staging with two- and threedimensional preoperative 3-T MR imaging. Radiology 254 (2):485-492

78. Fütterer JJ, Yakar D, Strijk SP, Barentsz JO (2008) Preoperative $3 \mathrm{~T}$ MR imaging of rectal cancer: local staging accuracy using a two-dimensional and three-dimensional T2-weighted turbo spin echo sequence. Eur J Radiol 65(1):66-71

79. Kim MJ, Lim JS, Oh YT, Kim JH, Chung JJ, Joo SH, Kim NK, Lee KY, Kim WH, Kim KW (2004) Preoperative MRI of rectal cancer with and without rectal water filling: an intraindividual comparison. AJR Am J Roentgenol 182(6):1469-1476

80. Piippo U, Pääkkö E, Mäkinen M, Mäkelä J (2008) Local staging of rectal cancer using the black lumen magnetic resonance imaging technique. Scand J Surg 97(3):237-242

81. Vliegen RF, Beets GL, von Meyenfeldt MF, Kessels AG, Lemaire EE, van Engelshoven JM, Beets-Tan RG (2005) Rectal cancer: MR imaging in local staging-is gadolinium-based contrast material helpful? Radiology 234(1):179-188

82. Rosenberg R, Herrmann K, Gertler R, Künzli B, Essler M, Lordick F, Becker K, Schuster T, Geinitz H, Maak M, Schwaiger M, Siewert JR, Krause B (2009) The predictive value of metabolic response to preoperative radiochemotherapy in locally advanced rectal cancer measured by PET/CT. Int J Colorectal Dis $24(2): 191-200$

83. Hosonuma T, Tozaki M, Ichiba N, Sakuma T, Hayashi D, Yanaga K, Fukuda K (2006) Clinical usefulness of diffusionweighted imaging using low and high $\mathrm{b}$-values to detect rectal cancer. Magn Reson Med Sci 5(4):173-177

84. Rao SX, Zeng MS, Chen CZ, Li RC, Zhang SJ, Xu JM, Hou YY (2008) The value of diffusion-weighted imaging in combination with T2-weighted imaging for rectal cancer detection. Eur J Radiol 65(2):299-303

85. Sasaki T, Shinya S, Nakagawa Y, Hisamatsu Y, Sukehiro S, Guiqing Z, Yamamoto F (2007) Diffusion-weighted imaging is a feasible method for screening colorectal cancer: report of a case. Hepatogastroenterology 54(79):1951-1953

86. Kim SH, Lee JM, Hong SH, Kim GH, Lee JY, Han JK, Choi BI (2009) Locally advanced rectal cancer: added value of diffusion- weighted MR imaging in the evaluation of tumor response to neoadjuvant chemo- and radiation therapy. Radiology 253 (1):116-125

87. Kim CK, Kim SH, Chun HK, Lee WY, Yun SH, Song SY, Choi D, Lim HK, Kim MJ, Lee J, Lee SJ (2006) Preoperative staging of rectal cancer: accuracy of 3-Tesla magnetic resonance imaging. Eur Radiol 16(5):972-980

88. Kim CK, Kim SH, Choi D, Kim MJ, Chun HK, Lee SJ, Lee JM (2007) Comparison between 3-T magnetic resonance imaging and multi-detector row computed tomography for the preoperative evaluation of rectal cancer. J Comput Assist Tomogr 31 (6):853-859

89. Chun HK, Choi D, Kim MJ, Lee J, Yun SH, Kim SH, Lee SJ, Kim CK (2006) Preoperative staging of rectal cancer: comparison of 3-T high-field MRI and endorectal sonography. AJR Am J Roentgenol 187(6):1557-1562

90. Winter L, Bruhn H, Langrehr J, Neuhaus P, Felix R, Hänninen LE (2007) Magnetic resonance imaging in suspected rectal cancer: determining tumor localization, stage, and sphinctersaving resectability at 3-Tesla-sustained high resolution. Acta Radiol 48(4):379-387

91. Kim SH, Lee JM, Lee MW, Kim GH, Han JK, Choi BI (2008) Diagnostic accuracy of 3.0-Tesla rectal magnetic resonance imaging in preoperative local staging of primary rectal cancer. Invest Radiol 43(8):587-593

92. Muthusamy VR, Chang KJ (2007) Optimal methods for staging rectal cancer. Clin Cancer Res 13(22 Pt 2):6877s-6884s

93. Dinter DJ, Hofheinz RD, Hartel M, Kaehler GF, Neff W, Diehl SJ (2008) Preoperative staging of rectal tumors: comparison of endorectal ultrasound, hydro-CT, and high-resolution endorectal MRI. Onkologie 31(5):230-235

94. Akin O, Nessar G, Agildere AM, Aydog G (2004) Preoperative local staging of rectal cancer with endorectal MR imaging: comparison with histopathologic findings. Clin Imaging 28(6):432-438

95. Torricelli P (2007) Rectal cancer staging. Surg Oncol 16(Suppl 1):S49-S50

96. Donmez FY, Tunaci M, Yekeler E, Balik E, Tunaci A, Acunas G (2008) Effect of using endorectal coil in preoperative staging of rectal carcinomas by pelvic MR imaging. Eur J Radiol 67 (1):139-145

97. Karantanas AH, Yarmenitis S, Papanikolaou N, Gourtsoyiannis N (2007) Preoperative imaging staging of rectal cancer. Dig Dis 25(1):20-32

98. Iafrate F, Laghi A, Paolantonio P, Rengo M, Mercantini P, Ferri M, Ziparo V, Passariello R (2006) Preoperative staging of rectal cancer with MR Imaging: correlation with surgical and histopathologic findings. Radiographics 26(3):701-714

99. Torkzad MR, Suzuki C, Tanaka S, Palmer G, Holm T, Blomqvist L (2008) Morphological assessment of the interface between tumor and neighboring tissues, by magnetic resonance imaging, before and after radiotherapy in patients with locally advanced rectal cancer. Acta Radiol 49(10):1099-1103

100. Torkzad MR, Lindholm J, Martling A, Cedermark B, Glimelius B, Blomqvist L (2007) MRI after preoperative radiotherapy for rectal cancer; correlation with histopathology and the role of volumetry. Eur Radiol 17(6):1566-1573

101. Allen SD, Padhani AR, Dzik-Jurasz AS, Glynne-Jones R (2007) Rectal carcinoma: MRI with histologic correlation before and after chemoradiation therapy. AJR Am J Roentgenol 188 (2):442-451

102. Dworak O, Keilholz L, Hoffmann A (1997) Pathological features of rectal cancer after preoperative radiochemotherapy. Int $\mathrm{J}$ Colorectal Dis 12(1):19-23

103. Rödel C, Martus P, Papadoupolos T, Füzesi L, Klimpfinger M, Fietkau R, Liersch T, Hohenberger W, Raab W, Sauer R, Wittekind C (2005) Prognostic significance of tumor regression 
after preoperative chemoradiotherapy for rectal cancer. J Clin Oncol 23(34):8688-8696

104. Jacques AE, Rockall AG, Alijani M, Hughes J, Babar S, Aleong JA, Cottrill C, Dorudi S, Reznek RH (2007) MRI demonstration of the effect of neoadjuvant radiotherapy on rectal carcinoma. Acta Oncol 46(7):989-995

105. Wieder HA, Rosenberg R, Lordick F, Geinitz H, Beer A, Becker K, Woertler K, Dobritz M, Siewert JR, Rummeny EJ, Stollfuss JC (2007) Rectal cancer: MR imaging before neoadjuvant chemotherapy and radiation therapy for prediction of tumorfree circumferential resection margins and long-term survival. Radiology 243(3):744-751

106. Kuo LJ, Liu MC, Jian JJ, Horng CF, Cheng TI, Chen CM, Fang WT, Chung YL (2007) Is final TNM staging a predictor for survival in locally advanced rectal cancer after preoperative chemoradiation therapy? Ann Surg Oncol 14(10):2766-2772

107. Wotherspoon AC (2006) Pathological assessment of rectal carcinoma after preoperative therapy. Colorectal Dis 8(Suppl 3):37-39

108. Vliegen RF, Beets GL, Lammering G, Dresen RC, Rutten HJ, Kessels AG, Oei TK, de Bruïne AP, van Engelshoven JM, BeetsTan RG (2008) Mesorectal fascia invasion after neoadjuvant chemotherapy and radiation therapy for locally advanced rectal cancer: accuracy of MR imaging for prediction. Radiology 246 (2):454-462

109. Kulkarni T, Gollins S, Maw A, Hobson P, Byrne R, Widdowson D (2008) Magnetic resonance imaging in rectal cancer downstaged using neoadjuvant chemoradiation: accuracy of prediction of tumour stage and circumferential resection margin status. Colorectal Dis 10(5):479-489

110. Barbaro B, Fiorucci C, Tebala C, Valentini V, Gambacorta MA, Vecchio FM, Rizzo G, Coco C, Crucitti A, Ratto C, Bonomo L (2009) Locally advanced rectal cancer: MR imaging in prediction of response after preoperative chemotherapy and radiation therapy. Radiology 250(3):730-739

111. Dresen RC, Beets GL, Rutten HJ, Engelen SM, Lahaye MJ, Vliegen RF, de Bruïne AP, Kessels AG, Lammering G, BeetsTan RG (2009) Locally advanced rectal cancer: MR imaging for restaging after neoadjuvant radiation therapy with concomitant chemotherapy. Part I. Are we able to predict tumor confined to the rectal wall? Radiology 252(1):71-80

112. Rudisch A, Kremser C, Judmaier W, Zunterer H, DeVries AF (2005) Dynamic contrast-enhanced magnetic resonance imaging: a non-invasive method to evaluate significant differences between malignant and normal tissue. Eur J Radiol 53 (3):514-519

113. Atkin G, Taylor NJ, Daley FM, Stirling JJ, Richman P, GlynneJones R, d'Arcy JA, Collins DJ, Padhani AR (2006) Dynamic contrast-enhanced magnetic resonance imaging is a poor measure of rectal cancer angiogenesis. Br J Surg 93(8):992-1000

114. Dinter DJ, Horisberger K, Zechmann C, Wenz F, Brade J, Willeke F, Neff KW, Schoenberg SO, Hofheinz RD (2009) Can dynamic MR imaging predict response in patients with rectal cancer undergoing cetuximab-based neoadjuvant chemoradiation? Onkologie 32(3):86-93

115. Myerson RJ, Hunt SR (2007) Conservative alternatives to extirpative surgery for rectal cancer. Clin Oncol (R Coll Radiol) 19(9):682-686

116. Beets-Tan RG, Beets GL (2003) Rectal cancer: how accurate can imaging predict the $\mathrm{T}$ stage and the circumferential resection margin? Int J Colorectal Dis 18(5):385-391

117. Kim SH, Lee JM, Park HS, Eun HW, Han JK, Choi BI (2009) Accuracy of MRI for predicting the circumferential resection margin, mesorectal fascia invasion, and tumor response to neoadjuvant chemoradiotherapy for locally advanced rectal cancer. J Magn Reson Imaging 29(5):1093-1101
118. Hughes R, Harrison M, Glynne-Jones R (2010) Could a wait and see policy be justified in T3/4 rectal cancers after chemoradiotherapy? Acta Oncol 49(3):378-381

119. Idrees K, Paty PB (2006) Early rectal cancer: transanal excision or radical surgery? Adv Surg 40:239-248

120. Srinivasaiah N, Joseph B, Mackey P, Monson JR (2008) How do we manage early rectal cancer? A national questionnaire survey among members of the ACPGBI after the preliminary results of the MRC CR07/NCIC CO16 randomized trial. Colorectal Dis 10 (4):357-362

121. Baatrup G, Endreseth BH, Isaksen V, Kjellmo A, Tveit KM, Nesbakken A (2009) Preoperative staging and treatment options in T1 rectal adenocarcinoma. Acta Oncol 48(3):328-342

122. Doornebosch PG, Tollenaar RA, De Graaf EJ (2009) Is the increasing role of transanal endoscopic microsurgery in curation for T1 rectal cancer justified? A systematic review. Acta Oncol 48(3):343-353

123. Khani MH, Smedh K, Kraaz W (2007) Is the circumferential resection margin a predictor of local recurrence after preoperative radiotherapy and optimal surgery for rectal carcinoma? Colorectal Dis 9(8):706-712

124. Stollfuss JC, Becker K, Sendler A, Seidl S, Settles M, Auer F, Beer A, Rummeny EJ, Woertler K (2006) Rectal carcinoma: high-spatial-resolution MR imaging and T2 quantification in rectal cancer specimens. Radiology 241(1):132-141

125. Koh DM, Chau I, Tait D, Wotherspoon A, Cunningham D, Brown G (2008) Evaluating mesorectal lymph nodes in rectal cancer before and after neoadjuvant chemoradiation using thinsection T2-weighted magnetic resonance imaging. Int J Radiat Oncol Biol Phys 71(2):456-461

126. Suppiah A, Hunter IA, Cowley J, Garimella V, Cast J, Hartley JE, Monson JR (2009) Magnetic resonance imaging accuracy in assessing tumour down-staging following chemoradiation in rectal cancer. Colorectal Dis 11(3):249-253

127. Lahaye MJ, Beets GL, Engelen SM, Kessels AG, de Bruïne AP, Kwee HW, van Engelshoven JM, van de Velde CJ, Beets-Tan RG (2009) Locally advanced rectal cancer: MR imaging for restaging after neoadjuvant radiation therapy with concomitant chemotherapy. Part II. What are the criteria to predict involved lymph nodes? Radiology 252 (1):81-91

128. Johnston DF, Lawrence KM, Sizer BF, Arulampalam TH, Motson RW, Dove E, Lacey N (2009) Locally advanced rectal cancer: histopathological correlation and predictive accuracy of serial MRI after neoadjuvant chemotherapy. Br J Radiol 82 (976):332-336

129. Chen CC, Lee RC, Lin JK, Wang LW, Yang SH (2005) How accurate is magnetic resonance imaging in restaging rectal cancer in patients receiving preoperative combined chemoradiotherapy? Dis Colon Rectum 48(4):722-728

130. O'Neill BD, Brown G, Heald RJ, Cunningham D, Tait DM (2007) Non-operative treatment after neoadjuvant chemoradiotherapy for rectal cancer. Lancet Oncol 8(7):625-633

131. Dahlberg M, Glimelius B, Påhlman L (1999) Changing strategy for rectal cancer is associated with improved outcome. Br J Surg 86(3):379-384

132. Burden C, Rose D, Daniels IR (2005) Bowel cancer: the outcome is improving. J R Soc Promot Health 125(6):255258

133. Daniels IR, Fisher SE, Heald RJ, Moran BJ (2007) Accurate staging, selective preoperative therapy and optimal surgery improves outcome in rectal cancer: a review of the recent evidence. Colorectal Dis 9(4):290-301

134. Messiou C, Chalmers AG, Boyle K, Wilson D, Sagar P (2008) Pre-operative MR assessment of recurrent rectal cancer. Br J Radiol 81(966):468-473 
135. Miucin-Vukadinović I, Kozić D, Adić O, Radovanović Z, Breberina M, Bokorov B (2008) Rectal cancer: possibilities of MRI in detection of local recurrence. Med Pregl 61(34):157-163

136. Höcht S, Mann B, Germer CT, Hammad R, Siegmann A, Wiegel T, Buhr HJ, Hinkelbein W (2004) Pelvic sidewall involvement in recurrent rectal cancer. Int J Colorectal Dis 19(2):108-113

137. Syk E, Torkzad MR, Blomqvist L, Ljungqvist O, Glimelius B (2006) Radiological findings do not support lateral residual tumour as a major cause of local recurrence of rectal cancer. Br J Surg 93(1):113-119

138. Syk E, Torkzad MR, Blomqvist L, Nilsson PJ, Glimelius B (2008) Local recurrence in rectal cancer: anatomic localization and effect on radiation target. Int J Radiat Oncol Biol Phys 72 (3):658-664

139. Titu LV, Nicholson AA, Hartley JE, Breen DJ, Monson JR (2006) Routine follow-up by magnetic resonance imaging does not improve detection of resectable local recurrences from colorectal cancer. Ann Surg 243(3):348-352

140. Schaefer O, Langer M (2007) Detection of recurrent rectal cancer with CT, MRI and PET/CT. Eur Radiol 17(8):2044-2054

141. Moran B, Brown G, Cunningham D, Daniels I, Heald R, Quirke P, Sebag-Montefiore D (2008) Clarifying the TNM staging of rectal cancer in the context of modern imaging and neo-adjuvant treatment: ' $y$ ' ' $u$ ' and 'p' need 'mr' and 'ct'. Colorectal Dis 10 (3):242-243 